\title{
Methanosarcina acetivorans contains a functional ISC system for iron-sulfur cluster biogenesis
}

\author{
Thomas M. Deere ${ }^{1}$, Divya Prakash², Faith H. Lessner ${ }^{1}$, Evert C. Duin ${ }^{3}$ and Daniel J. Lessner ${ }^{1 *}$ (D)
}

\begin{abstract}
Background: The production of methane by methanogens is dependent on numerous iron-sulfur (Fe-S) cluster proteins; yet, the machinery involved in Fe-S cluster biogenesis in methanogens remains largely unknown. Methanogen genomes encode uncharacterized homologs of the core components of the ISC (IscS and IscU) and SUF (SufBC) Fe-S cluster biogenesis systems found in bacteria and eukaryotes. Methanosarcina acetivorans contains three iscSU and two SufCB gene clusters. Here, we report genetic and biochemical characterization of M. acetivorans iscSU2.

Results: Purified IscS2 exhibited pyridoxal 5'- phosphate-dependent release of sulfur from L-cysteine. Incubation of purified IscU2 with IscS2, cysteine, and iron $\left(\mathrm{Fe}^{2+}\right)$ resulted in the formation of [4Fe-4S] clusters in IscU2. IscU2 transferred a [4Fe-4S] cluster to purified M. acetivorans apo-aconitase. IscU2 also restored the aconitase activity in airexposed M. acetivorans cell lysate. These biochemical results demonstrate that IscS2 is a cysteine desulfurase and that IscU2 is a Fe-S cluster scaffold. M. acetivorans strain DJL60 deleted of iscSU2 was generated to ascertain the in vivo importance of IscSU2. Strain DJL60 had Fe-S cluster content and growth similar to the parent strain but lower cysteine desulfurase activity. Strain DJL60 also had lower intracellular persulfide content compared to the parent strain when cysteine was an exogenous sulfur source, linking IscSU2 to sulfur metabolism.
\end{abstract}

Conclusions: This study establishes that M. acetivorans contains functional IscS and IscU, the core components of the ISC Fe-S cluster biogenesis system and provides the first evidence that ISC operates in methanogens.

\section{Background}

Iron-sulfur (Fe-S) clusters are ubiquitous protein cofactors that are involved in numerous cellular processes, such as respiration, photosynthesis, DNA repair, and regulation. A primary function of $\mathrm{Fe}-\mathrm{S}$ clusters in proteins is to mediate the transfer of electrons during oxidation-reduction reactions [1]. As such, Fe-S proteins serve critical roles in energy-conservation pathways in almost all organisms and in steps leading to the production of valuable metabolic products, including biofuels (e.g. $\mathrm{H}_{2}$ ) [2, 3]. Simple Fe-S clusters include [2Fe-2S],

\footnotetext{
* Correspondence: dlessner@uark.edu

'Department of Biological Sciences, University of Arkansas-Fayetteville, Fayetteville, AR 72701, USA

Full list of author information is available at the end of the article
}

[3Fe-4S], and [4Fe-4S] clusters, with the [4Fe-4S] cluster being the most prevalent $[1,4]$. The metabolism of many organisms also relies on enzymes that use more complex Fe-S clusters, such as those found in the biotechnology relevant enzymes hydrogenase, carbon monoxide dehydrogenase, and nitrogenase [5-7]. For example, nitrogenase contains a $[8 \mathrm{Fe}-7 \mathrm{~S}]$ cluster and a Mo-8Fe-9S-Chomocitrate cluster, in addition to [4Fe-4S] clusters [8].

Although Fe-S clusters in proteins are typically oxygen-labile, aerobes rely on $\mathrm{Fe}-\mathrm{S}$ proteins as obligate components of respiratory systems [1]. However, Fe-S proteins are far more abundant in strict anaerobes, specifically those that grow by respiration. Among anaerobes, methanogenic archaea (methanogens) and acetogenic bacteria (acetogens) are predicted to contain 
the highest number of [4Fe-4S] cluster proteins, indicating that this cluster is critical for methanogenesis and acetogenesis [4,9]. Methanogenesis is a critical step in the global carbon cycle and in the production of methane as a biofuel. Numerous Fe-S proteins are involved in methanogenesis [10-12]. For example, [4Fe-4S] cluster-containing ferredoxin serves as a primary electron carrier and [4Fe-4S] cluster-containing heterodisulfide reductase plays a central role, including in electron bifurcation [13, 14]. Recently, the bifurcating hydrogenase/heterodisulfide reductase complex was shown to be a dimer of protomers containing 22 [4Fe-4S] clusters, while the bifunctional formyl-methanofuran dehydrogenase complex, which catalyzes the reversible reduction of $\mathrm{CO}_{2}$ to formyl-methanofuran, was shown to contain a remarkable 46 electronically coupled [4Fe-4S] clusters [15]. Many additional [4Fe-4S] proteins are involved in the metabolism of methanogens, including several biosynthesis enzymes and regulatory proteins. Several information processing enzymes in methanogens also harbor [4Fe-4S] clusters, such as RNA polymerase [16]. In addition, methanogens, along with related anaerobic methanotrophs, are the only archaea that possess nitrogenase and are therefore capable of nitrogen fixation [17-19]. Despite methanogenesis having an absolute requirement for Fe-S proteins, the factors and mechanisms used by methanogens to assemble and traffic simple and complex Fe-S clusters remain largely unknown.

Two generalized systems (ISC and SUF) are known to function in the biogenesis of $\mathrm{Fe}-\mathrm{S}$ clusters in bacteria and eukaryotes. A third system (NIF) is specific to biogenesis of the simple and complex Fe-S clusters in the components of nitrogenases found in bacteria [20-23]. For general $\mathrm{Fe}-\mathrm{S}$ cluster biogenesis, bacteria typically have ISC but may have SUF alone or both ISC and SUF systems (e.g. Escherichia coli). ISC is the primary system in E. coli, whereas SUF appears important during times of increased oxidative stress and/or Fe limitation [20]. In eukaryotes, the ISC system functions in mitochondria, and the SUF system is primarily present in chloroplasts [23, 24]. The core components of all three systems include a pyridoxal 5' - phosphate (PLP)-dependent cysteine desulfurase (IscS, SufS, or NifS) that liberates sulfur from cysteine, forming a persulfide, followed by sulfur transfer to an Fecontaining scaffold (IscU, SufB(D)C, or NifU). The Fe-S cluster is assembled on the scaffold and subsequently delivered to target apo-proteins, often with the help of accessory and/or carrier proteins. Other accessory proteins may also be involved in cluster assembly $[20,22,23]$. The core scaffold of the SUF system (SufBC) appears universally encoded in the genomes of archaea, and many archaeal genomes also encode homologs of the minimal components of the ISC system (IscS and IscU) [25]. The functional role(s) of these components in archaea are poorly understood.
All sequenced methanogens contain at least one sufBC gene cluster, typically arranged as $\operatorname{sufC}$ then $\operatorname{sufB}[25]$. Thus, SufBC may serve as a general Fe-S cluster scaffold in all methanogens. Many sequenced methanogen genomes also encode homologs of IscS and IscU, typically arranged as iscSU. Methanogen genomes do not encode NifS or NifU, indicating that methanogens lack a nitrogenase-specific Fe-S cluster biogenesis system. To begin to understand the role and importance of IscSU to methanogens, we report here the genetic and biochemical characterization of IscSU from the genetically tractable methanogen Methanosarcina acetivorans.

\section{Results}

M. acetivorans contains three distinct iscSU gene clusters

The genome of $M$. acetivorans contains three isc gene clusters, each arranged as iscSU, and lacking the additional genes found in bacteria, such as in the wellcharacterized isc operon of E. coli (Fig. S1) [26]. We have designated the three iscSU clusters in $M$. acetivorans as $i s c 1$, isc 2 , and isc 3 , based on gene annotation order. The iscS1 and iscU1 genes are clustered with four additional genes of unknown function. A similar gene arrangement is found in other Methanosarcina species including Methanosarcina barkeri and Methanosarcina mazei. The $i s c S 2$ and iscU2 genes are clustered with genes encoding enzymes involved in methionine and NAD biosynthesis. A similar gene arrangement is present in many Methanomicrobia, including $M$. barkeri. The genes encoding IscS3 and IscU3 are not clustered with additional genes. A similar gene cluster is found in both M. barkeri and M. mazei.

IscS1, IscS2, and IscS3 share 45-61\% sequence identity to each other, and each is similar in molecular weight and sequence identity to well-characterized IscS from $E$. coli (Table 1). The PLP-binding and active site residues identified in E. coli IscS are conserved in the $M$. acetivorans IscS homologs, except for PLP-binding residues in IscS1 (Table 1 and Fig. S2) [27]. IscU1, IscU2, and IscU3 share $49-68 \%$ sequence identity to each other, and each protein also has $>50 \%$ sequence identity to $E$. coli $\mathrm{IscU}$ (Table 1). The Fe-S cluster binding/transfer and Hsp70 chaperone (HscA)-interacting residues (LPPVK) identified in $E$. coli IscU are conserved in the three M. acetivorans IscU proteins [24, 28]. However, one of the cysteines involved in Fe-S cluster binding by E. coli $\mathrm{IscU}$ is replaced with histidine in $M$. acetivorans IscU3 (Table 1 and Fig. S3). Outside of methanogens, $M$. acetivorans IscS and IscU homologs have highest sequence identity (50-68\%) to putative IscS and IscU proteins found in Clostridia (e.g. Ruminiclostridium thermocellum), consistent with some genes in Methanosarcina acquired from Clostridia via horizontal transfer [29]. These results indicate that $M$. acetivorans possesses three distinct copies of the core components of the ISC system. However, some of the functionally 
Table 1 Comparison of predicted M. acetivorans IscS and IscU

\begin{tabular}{|c|c|c|c|c|c|}
\hline $\begin{array}{l}\text { Canonical } \\
\text { Protein (kDa) }\end{array}$ & $\begin{array}{l}\text { Functional motif(s) or } \\
\text { residues }\end{array}$ & $\begin{array}{l}\text { M. acetivorans } \\
\text { homolog }\end{array}$ & Gene ID: & $\begin{array}{l}\text { Percent identity to } E \text {. } \\
\text { coli IscS/U }\end{array}$ & $\begin{array}{l}\text { Motif or residues in corresponding } M \text {. } \\
\text { acetivorans protein }\end{array}$ \\
\hline \multirow[t]{3}{*}{$\begin{array}{l}\text { E. coli IscS (45.1 } \\
\mathrm{kDa})\end{array}$} & 323-SSGSACTS-330 & $\begin{array}{l}\text { IscS1: MA0808 } \\
(42.2 \mathrm{kDa})\end{array}$ & $\begin{array}{l}\text { MA- } \\
\text { RS04215 }\end{array}$ & 43 & 318-STGSACFS-325 \\
\hline & & $\begin{array}{l}\text { IscS2: MA2718 } \\
(43.3 \mathrm{kDa})\end{array}$ & $\begin{array}{l}\text { MA- } \\
\text { RS14225 }\end{array}$ & 48 & 232-STGSACNS-330 \\
\hline & & $\begin{array}{l}\text { IscS3: MA3264 } \\
\text { (43.6 kDa) }\end{array}$ & $\begin{array}{l}\text { MA } \\
\text { RS17030 }\end{array}$ & 48 & 317-STGSACSS-324 \\
\hline \multirow[t]{3}{*}{$\begin{array}{l}\text { E. coli IscU }(13.8 \\
\mathrm{kDa})\end{array}$} & $\begin{array}{l}\text { C37, D39, C63, C106 } \\
\text { 99-LPPVK-103 }\end{array}$ & $\begin{array}{l}\text { IscU1: MA0807 } \\
(24.2 \mathrm{kDa})\end{array}$ & $\begin{array}{l}\text { MA- } \\
\text { RS04210 }\end{array}$ & 50 & $\begin{array}{l}\text { C45, D47, C72, C116 } \\
\text { 109-LPPIK-113 }\end{array}$ \\
\hline & & $\begin{array}{l}\text { IscU2: MA2717 } \\
(13.9 \mathrm{kDa})\end{array}$ & $\begin{array}{l}\text { MA } \\
\text { RS14220 }\end{array}$ & 54 & $\begin{array}{l}\text { C34, D36, C59, C103 } \\
\text { 96-LPPIK-100 }\end{array}$ \\
\hline & & $\begin{array}{l}\text { IscU3: MA3265 } \\
\text { (14.0 kDa) }\end{array}$ & $\begin{array}{l}\text { MA_ } \\
\text { RS17035 }\end{array}$ & 50 & $\begin{array}{l}\text { H32, D34, C57, C101 } \\
\text { 94-LPPGK-98 }\end{array}$ \\
\hline
\end{tabular}

${ }^{a}$ Cysteine desulfurase active site motif

${ }^{b}$ Residues critical for Fe-S cluster binding and transfer

c Residues critical for interaction with the HscA chaperone

${ }^{\mathrm{d}}$ Detected in M. acetivorans proteome (see text)

important residues in E. coli IscS and IscU are not conserved in IscS1 and IscU3, respectively, Furthermore, only IscS2 and IscU2 have been consistently detected in the proteome of $M$. acetivorans [30-33], indicating that IscS2 and IscU2 may serve as the primary ISC system. Thus, IscS2 and IscU2 were chosen for initial biochemical and genetic characterization.

\section{IscS2 is a cysteine desulfurase}

Recombinant IscS2 was over-produced in E. coli and purified to homogeneity (Fig. 1a). Purified IscS2 was pale-yellow and exhibited an UV-visible spectrum with an absorbance maximum at $420 \mathrm{~nm}$ (Fig. 1b), consistent with the presence of PLP [34]. Purified IscS2 was able to remove sulfur from L-cysteine (Table 2) confirming IscS2 is a cysteine desulfurase. To determine if the cysteine desulfurase activity of IscS2 is dependent on PLP and if recombinant IscS2 contained full incorporation of PLP, assays were performed in the presence and absence of PLP (Table 2). A 57\% increase in the cysteine desulfurase activity of IscS2 was observed when PLP was added to the assay. IscS2 reconstituted with PLP $\left(\mathrm{IscS} 2^{\mathrm{PLP}}\right.$ ) exhibited the same specific activity both in the absence and presence of additional PLP. An increase in the absorbance at $420 \mathrm{~nm}$ was also observed with IscS2 ${ }^{\text {PLP }}$ (Fig. 1b). These data are consistent with full incorporation of PLP in IscS2 $2^{\mathrm{PLP}}$. IscS2 ${ }^{\mathrm{PLP}}$ was used in all subsequent experiments. Size-exclusion chromatography of IscS2 ${ }^{\mathrm{PLP}}$ revealed the purified protein exists as a homodimer (Fig. 1c), similar to previously characterized IscS $[27,34]$. Taken together, these results reveal that IscS2 is a PLP-dependent cysteine desulfurase.

\section{IscU2 is capable of binding Fe-S clusters}

Recombinant IscU2 was expressed in E. coli and purified to homogeneity under anoxic conditions (Fig. 2a).
Purified IscU2 was pale-red and exhibited an UV-visible spectrum with minor absorbance maxima at $360 \mathrm{~nm}$ and $438 \mathrm{~nm}$ (Fig. 2b). As-purified IscU2 contained both iron and acid-labile sulfide (Table 3). However, the $\mathrm{A}_{438} / \mathrm{A}_{280}$ ratio and the iron/sulfide content was low indicating that a substantial portion of purified IscU2 was devoid of Fe-S clusters. IscU devoid of cluster (apo-IscU) typically exists as a monomer and subsequently dimerizes upon incorporation of [2Fe-2S] clusters. The two [2Fe-2S] clusters in dimeric IscU can then reductively couple to form a single [4Fe-4S] cluster [35, 36]. Size-exclusion chromatography of as-purified IscU2 yielded a major peak consistent with monomeric IscU2 and a minor peak consistent with dimeric IscU2 (Fig. 2c), indicating that the majority of aspurified IscU2 is in the apo-form. To test the ability of IscU2 to bind Fe-S clusters, IscS2-dependent and chemicaldependent reconstitution of $\mathrm{Fe}-\mathrm{S}$ clusters in IscU2 were performed. IscS2-dependent reconstituted IscU2 $\left(\mathrm{IscU} 2^{\mathrm{S}-\mathrm{FeS}}\right)$ was generated by the anoxic incubation of aspurified IscU2 with cysteine, iron and a catalytic amount of IscS2. Chemical-dependent reconstituted IscU (IscU2 ${ }^{\text {C-FeS }}$ ) was generated by the anoxic incubation of as-purified IscU2 with a molar excess of sodium sulfide and iron. A substantial increase in the iron and acid-labile sulfur content and the $\mathrm{A}_{438} / \mathrm{A}_{280}$ ratio was observed for both IscU2 ${ }^{\mathrm{S}-\mathrm{FeS}}$ and IscU2 ${ }^{\mathrm{C}-\mathrm{FeS}}$ (Table 3), consistent with an increase in $\mathrm{Fe}-\mathrm{S}$ clusters in both samples. The UV-visible spectra of $\mathrm{IscU} 2^{\mathrm{S}-\mathrm{FeS}}$ and $\mathrm{IscU} 2^{\mathrm{C}-\mathrm{FeS}}$ were similar and showed a substantial increase in the absorbance at $360 \mathrm{~nm}$ and $438 \mathrm{~nm}$ (Fig. 2b). Size-exclusion chromatography revealed IscU2 ${ }^{\mathrm{C}-\mathrm{FeS}}$ was dimeric (Fig. 2c), demonstrating that Fe-S cluster binding causes dimerization of IscU2. The UVvisible spectra and levels of iron and sulfur in $\mathrm{IscU}_{2} 2^{\mathrm{S}-\mathrm{FeS}}$ and $\mathrm{IscU} 2^{\mathrm{C}-\mathrm{FeS}}$ are consistent with the presence of a two [2Fe-2S] clusters or a single [4Fe-4S] cluster per dimer. 


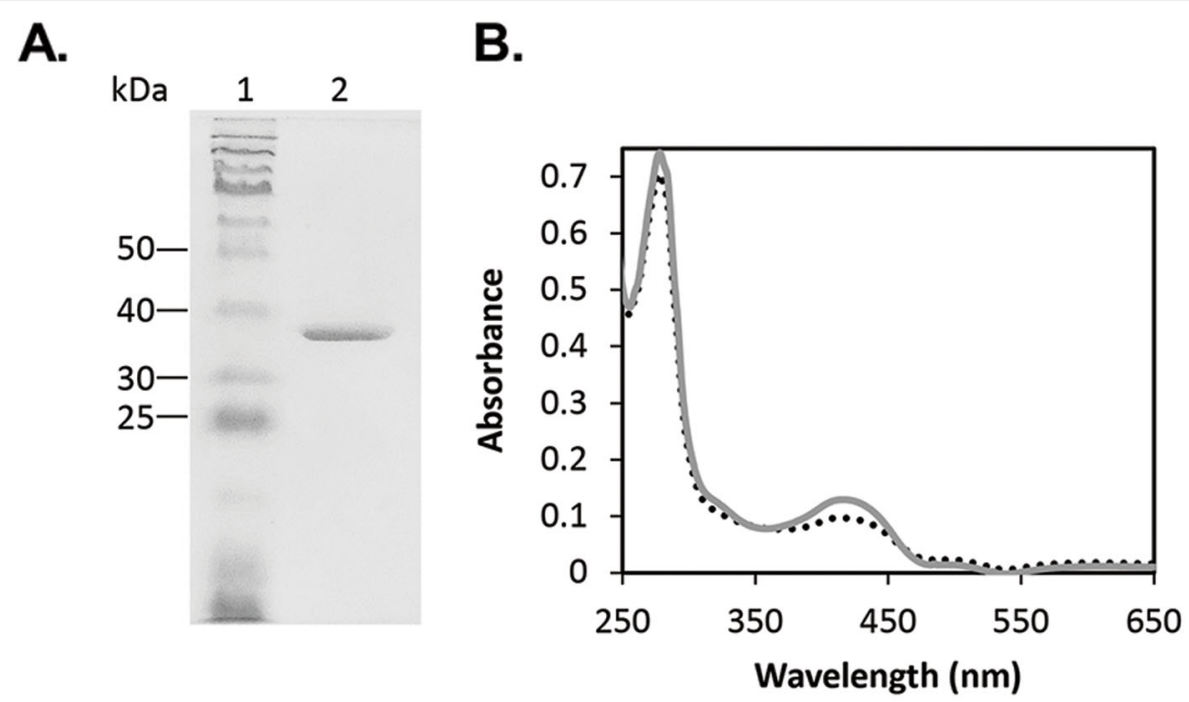

C.

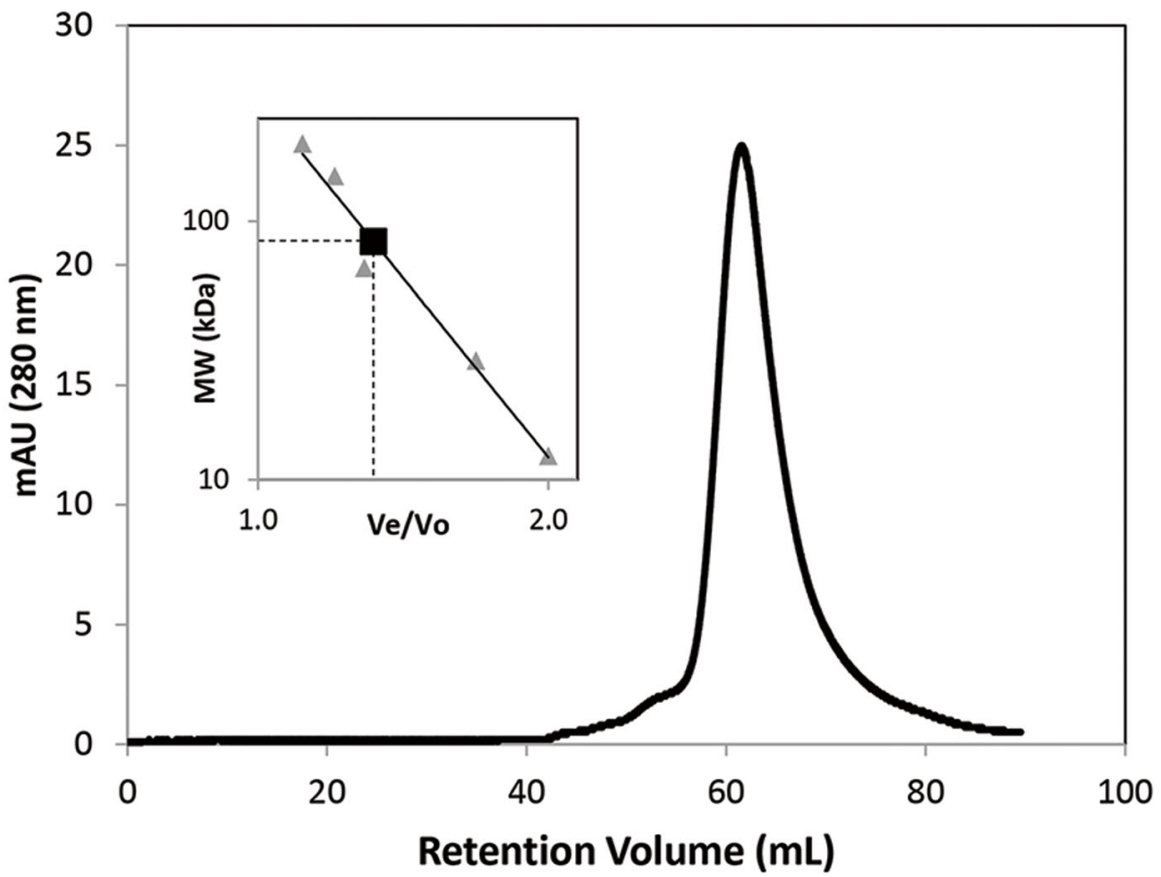

Fig. 1 Purified IscS2 binds PLP and is a homodimer. a SDS-PAGE analysis of purified IscS2 (cropped image of original). Lane 1, MW marker; lane 2, IscS2 $(2.5 \mu \mathrm{g})$. b UV-visible spectra of $20 \mu \mathrm{M}$ IscS2 (dotted line) or IscS2PLP (solid line) in $50 \mathrm{mM}$ Tris pH 7.2, $150 \mathrm{mM}$ NaCl. c Size-exclusion chromatography of IscS2. IscS2 (3.3 mg loaded) was analyzed by size-exclusion chromatography with $50 \mathrm{mM}$ Tris pH 8.0, $150 \mathrm{mM} \mathrm{NaCl}, 2 \mathrm{mM} \mathrm{DTT}$, $10 \%$ glycerol. The molecular weight of IscS2 was calculated from a standard curve (inset). The square represents the $\mathrm{V}_{\mathrm{e}} \mathrm{N}_{\mathrm{o}}$ of IscS2 with a calculated molecular weight of $84 \mathrm{kDa}$, consistent with homodimer $(87 \mathrm{kDa})$

EPR analysis of the as-purified IscU2 did not produce a signal under the conditions tested (data not shown), likely due to the low Fe-S cluster content. However, both $\mathrm{IscU} 2^{\mathrm{S}-\mathrm{FeS}}$ and $\mathrm{IscU} 2^{\mathrm{C}-\mathrm{FeS}}$ generated EPR spectra upon the addition of dithionite (Fig. 3). Both reduced samples showed a similar EPR signal that can be attributed to $[4 \mathrm{Fe}-4 \mathrm{~S}]^{+}$clusters, consistent with reductive coupling of the $[2 \mathrm{Fe}-2 \mathrm{~S}]$ clusters into a single $[4 \mathrm{Fe}-4 \mathrm{~S}]$ in dimeric
IscU2 [35]. From the presence of signals at around $g=2$ $(330 \mathrm{mT})$ and higher $g$ values (lower field values) it can be concluded that the clusters display several different spin states. The signal in the $300-400 \mathrm{mT}$ region are due to $\mathrm{S}=1 / 2$ species. The peak at $g=4.3$ is due to the spin $\pm 3 / 2$ doublet of an $S=5 / 2$ species with $E / D=0.333$. This peak can be due to a $4 \mathrm{Fe}$ cluster or adventitiously bound iron. The peaks at $g=5.09$ and 6.23 are due to 
Table 2 Effect of PLP on cysteine desulfurase activity of purified IscS2

\begin{tabular}{|c|c|}
\hline Sample & Cysteine desulfurase activity \\
\hline IscS2 & $21.5 \pm 1.2$ \\
\hline $\operatorname{IscS} 2+P L P$ & $33.8 \pm 0.5$ \\
\hline $\operatorname{IscS2} 2^{\mathrm{PLPa}}$ & $35.1 \pm 2.1$ \\
\hline$I S C S 2^{P L P}+P L P$ & $33.4 \pm 0.5$ \\
\hline
\end{tabular}

${ }^{\mathrm{a}}$ IscS2 reconstituted with PLP

${ }^{b}$ Cysteine desulfurase activity (nmol sulfur $\mathrm{min}^{-1} \mathrm{mg}^{-1}$ IscS2) of $5 \mu \mathrm{M}$ IscS2 or IscS2 ${ }^{\text {PLP }}$ in the absence or presence of additional PLP $(50 \mu \mathrm{M})$. Results are means from triplicates \pm 1 standard deviation

the spin $\pm 1 / 2$ doublet of an $S=5 / 2$ species with $E / D=$ 0.032 , the peak at $g=5.56$ is due to the same spin state but is due to the spin $\pm 3 / 2$ doublet. The peak at $g=7.52$ is due to the spin $\pm 1 / 2$ doublet of a $S=7 / 2$ species with $\mathrm{E} / \mathrm{D}=0$. The as-such sample (Fig. 3a, trace $\mathrm{C}$ ) does not show signals due to $[4 \mathrm{Fe}-4 \mathrm{~S}]^{2+}$ since in that redox state the spin is 0 . The sharp signal at around $330 \mathrm{mT}$ is due to a $[3 \mathrm{Fe}-4 \mathrm{~S}]^{1+}$ species. The multitude of spin states point towards a highly variable environment for the clusters present in the binding site on IscU2. These results are consistent with IscU2 as an Fe-S cluster scaffold protein, whereby IscS2 can catalyze the formation of [4Fe-4S] clusters in apo-IscU2 in the presence of iron and cysteine.

\section{M. acetivorans contains a [4Fe-4S] cluster aconitase}

Aconitase is a member of the dehydratase family of enzymes that requires a $[4 \mathrm{Fe}-4 \mathrm{~S}]$ cluster for activity and is the most common acceptor protein used in Fe-S cluster transfer assays [20]. The activity of aconitase can be measured spectrophotometrically in a coupled assay with isocitrate dehydrogenase, whereby the reduction of $\mathrm{NADP}^{+}$with isocitrate is measured at $340 \mathrm{~nm}$ [37]. IscU from several organisms is documented to transfer clusters to apo-aconitase [38-40]. Given the substantial information on cluster transfer to aconitase by IscU, aconitase is an ideal acceptor protein to initially assess cluster transfer from IscU2. $M$. acetivorans encodes a single aconitase homolog (MA0250), and M. acetivorans cell lysate contains detectable aconitase activity (5.2 nmol NADPH $\mathrm{min}^{-1} \mathrm{mg}^{-1}$ protein) as measured by the coupled assay. Recombinant MA0250 was expressed in E. coli and purified to homogeneity (Fig. S4A). Aspurified MA0250 lacked aconitase activity. However,

Table 3 Comparison of the properties of purified M. acetivorans IscU2

\begin{tabular}{|c|c|c|c|c|}
\hline Protein & $A_{438} / A_{280}$ & $\varepsilon_{438}\left(\mathrm{mM}^{-1} \mathrm{~cm}^{-1}\right)$ & $\operatorname{Iron}^{\mathrm{a}}$ & Sulfide $^{b}$ \\
\hline $\mathrm{IscU2}$ & 0.10 & 0.90 & $0.57 \pm 0.06$ & $0.44 \pm 0.04$ \\
\hline $\mathrm{IscU} 2^{\mathrm{C}-\mathrm{FeS}}$ & 0.26 & 6.07 & $2.47 \pm 0.11$ & $1.99 \pm 0.24$ \\
\hline $\mathrm{IscU} 2^{\mathrm{S}-\mathrm{FeS}}$ & 0.27 & 5.91 & $3.15 \pm 0.24$ & $3.15 \pm 0.39$ \\
\hline
\end{tabular}

${ }^{\mathrm{a}} \mathrm{nmol}$ iron/nmol of IscU2

${ }^{b} \mathrm{nmol}$ acid-labile sulfide/nmol of IscU2 after chemical reconstitution with iron and sulfide, purified MA0250 exhibited robust aconitase activity (100 nmol NADPH $\mathrm{min}^{-1} \mathrm{mg}^{-1}$ protein) and a broad absorbance maximum around $400 \mathrm{~nm}$ in UV-visible spectrum, consistent with the presence of a [4Fe-4S] cluster (Fig. S4B). These results reveal that MA0250 is an aconitase (designated here as AcnA) with activity dependent on the presence of a $[4 \mathrm{Fe}-4 \mathrm{~S}]$ cluster.

\section{Cluster-loaded IscU2 can restore the activity of $M$. acetivorans apo-aconitase}

Anoxic incubation of apo-AcnA with $\mathrm{IscU}^{\mathrm{S}-\mathrm{FeS}}$ resulted in rapid and complete recovery of aconitase activity, whereas incubation with iron and sulfide, at the same molar concentration as found in $\mathrm{Isc} U 2^{\mathrm{S}-\mathrm{FeS}}$, did not restore any activity to apo-AcnA over the same timeframe (Fig. 4). The ability of cluster loaded IscU2 to restore aconitase activity was also examined using cell lysate. Consistent with AcnA containing an oxygen-labile [4Fe-4S] cluster required for activity, exposure of cell lysate to air resulted in a complete loss of aconitase activity, even when the cell lysate was made anoxic again (Table 4). The addition of as-purified IscU2 during the anoxic incubation of air-exposed lysate also did not restore aconitase activity. However, anoxic incubation of air-exposed cell lysate with IscU2 ${ }^{\mathrm{S}-\mathrm{FeS}}$ partially restored aconitase activity (Table 4 ). Overall, these data demonstrate that cluster-loaded IscU2 is capable of transferring Fe-S clusters to apo-AcnA, consistent with IscU2 as an Fe-S cluster scaffold.

\section{Deletion of iscSU2 impacts sulfur metabolism in $M$. acetivorans}

The results from the biochemical characterization of recombinant IscS2 and IscU2 reveal properties consistent with each protein functioning in $\mathrm{Fe}-\mathrm{S}$ cluster biogenesis. To determine the importance of IscS2 and IscU2 to $M$. acetivorans physiology, a mutant strain (DJL60) was generated with iscSU2 deleted and replaced with the pac$h p t$ genes (Fig. 5a). The mutant was isolated using HS medium supplemented with both cysteine and sulfide. PCR (Fig. 5b) and DNA sequencing verified the DJL60 mutant. Thus, neither IscS2 nor IscU2 are essential to M. acetivorans.

To test the impact of the loss of IscSU2 on M. acetivorans, first the growth of strain DJL60 with cysteine, sulfide, or cysteine + sulfide was compared to the parent strain WWM73. Growth studies were performed in HS medium supplemented with $1.5 \mathrm{mM}$ dithiothreitol (DTT), designated here as $\mathrm{HS}_{\mathrm{DTT}}$ medium, to maintain similar redox conditions with the different sulfur sources. DTT cannot be used as a sulfur source by $M$. acetivorans [41]. The growth profiles of strains WWM73 and DJL60 were similar with the different exogenous sulfur sources (Fig. 6). However, compared to strain 


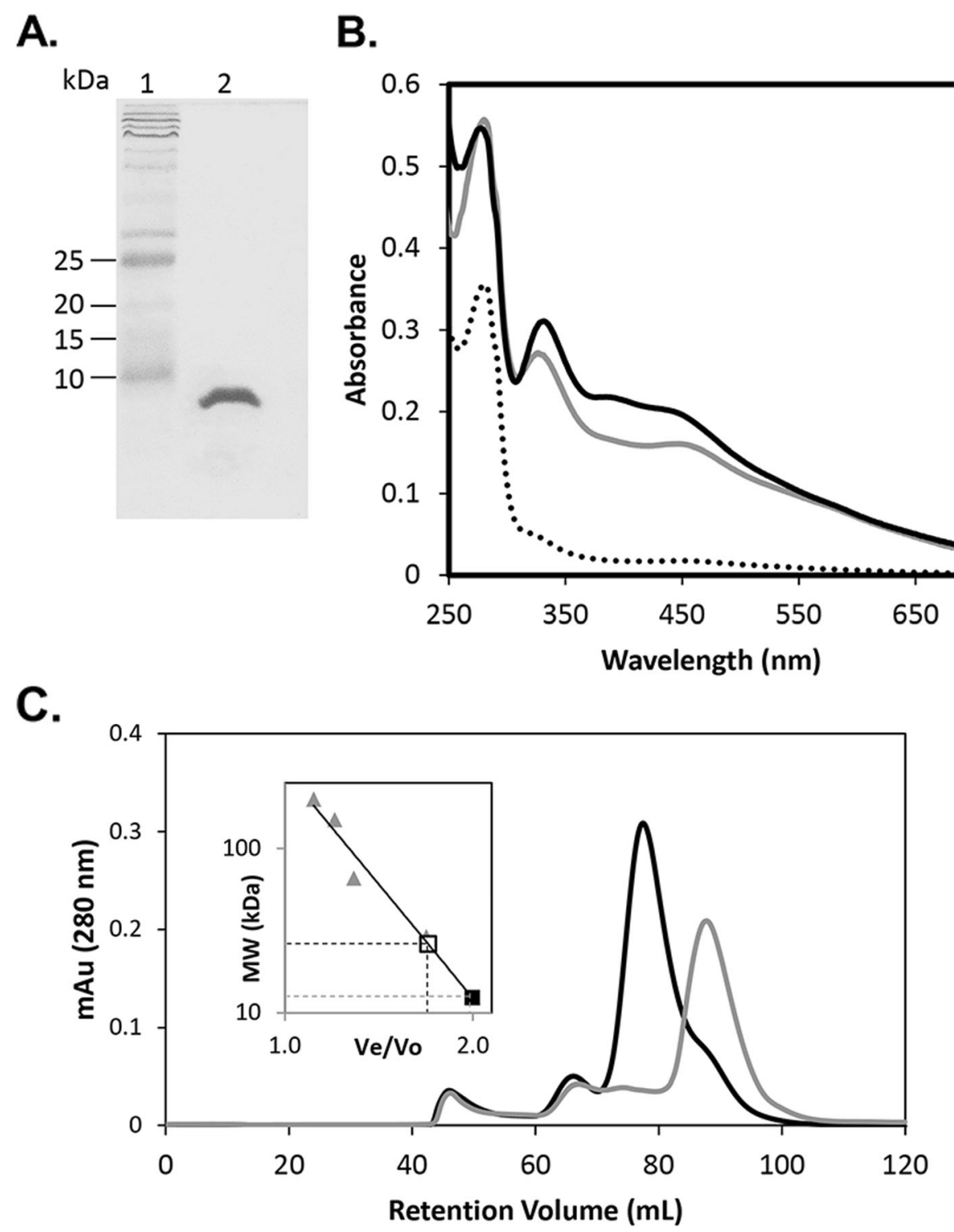

Fig. 2 Fe-S cluster reconstitution of purified IscU2. a SDS-PAGE analysis of purified IscU2 (cropped image of original). Lane 1, MW marker; lane 2, IscU2 $\left(2.4 \mu \mathrm{g}\right.$ ). b Anaerobic UV-visible spectra of $20 \mu \mathrm{M}$ IscU2 (dotted line), IscU2 ${ }^{\mathrm{S}-F e s}$ (black line) and IscU2 ${ }^{\mathrm{C}-\mathrm{Fes}}$ (gray line) in $50 \mathrm{mM}$ Tris pH 7.2, $150 \mathrm{mM} \mathrm{NaCl}$. c Anaerobic size exclusion chromatography of $14.8 \mathrm{mg}$ of IscU2 (gray line) and $15.6 \mathrm{mg}$ of IscU2 ${ }^{\mathrm{C}-\mathrm{Fes}}$ (black line) in $50 \mathrm{mM}$ Tris $\mathrm{pH}$ 8.0, $150 \mathrm{mM} \mathrm{NaCl}, 2 \mathrm{mM}$ DTT, 10\% glycerol. The molecular weight of IscU2 and IscU2 ${ }^{\mathrm{C}-\mathrm{FeS}}$ were calculated with a standard curve (inset). The calculated MW of IscU2 (solid square symbol) was $12 \mathrm{kDa}$ and the calculated MW of IscU2 ${ }^{\mathrm{C}-\mathrm{Fes}}$ (open square symbol) was $26 \mathrm{kDa}$

WWM73, strain DJL60 exhibited slightly slower and more variable growth when cysteine was present, especially when cysteine was the only sulfur source.

To determine the impact of the loss of IscSU2 on sulfur metabolism of $M$. acetivorans with the different exogenous sulfur sources, cysteine desulfurase activity, Fe-S cluster levels and persulfide content in lysate from strain DJL60 and WWM73 cells were determined. Importantly, lysate from strain DJL60 grown under all conditions exhibited significantly less cysteine desulfurase activity than strain WWM73 lysate (Fig. 7a), consistent with IscS2 as a functional in vivo cysteine desulfurase. However, cysteine desulfurase activity was not completely abolished in strain DJL60 indicating additional enzymes (e.g. IscS3) contribute to the total cysteine desulfurase activity. Interestingly, lysate from Methanococcus maripaludis, whose genome does not encode a cysteine desulfurase, contains some cysteine desulfurase activity from an unknown source [42]. No significant difference was observed in the Fe-S cluster content in strain DJL60 and WWM73 lysate across all sulfur conditions (Fig. 7b). However, the persulfide content in strain DJL60 was significantly lower in lysate from cysteine and cysteine + sulfide grown 
A.

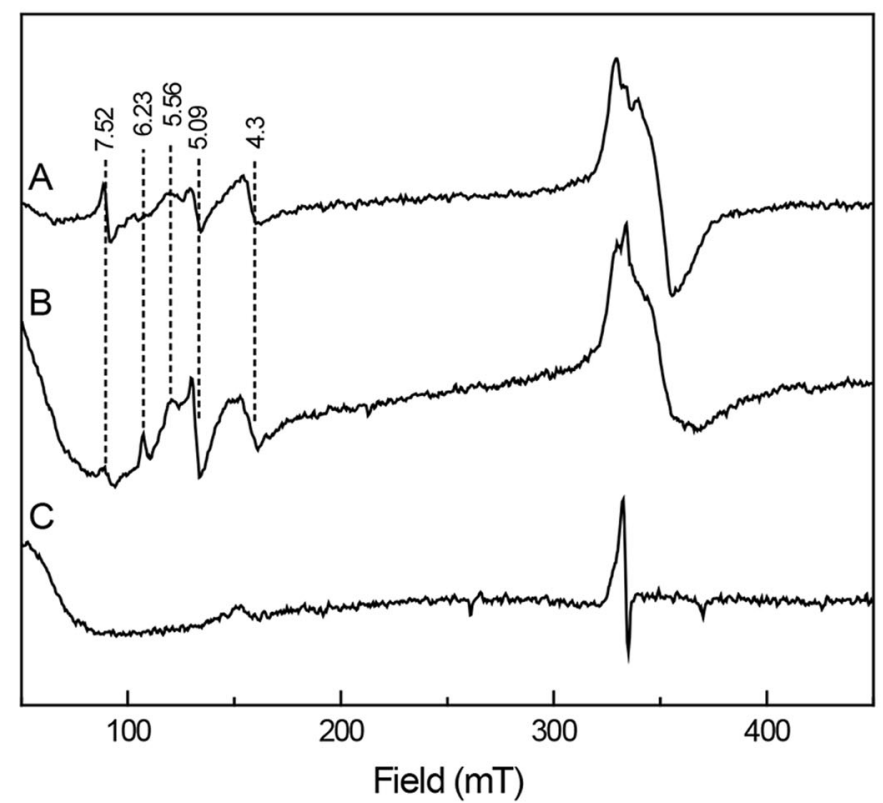

B.

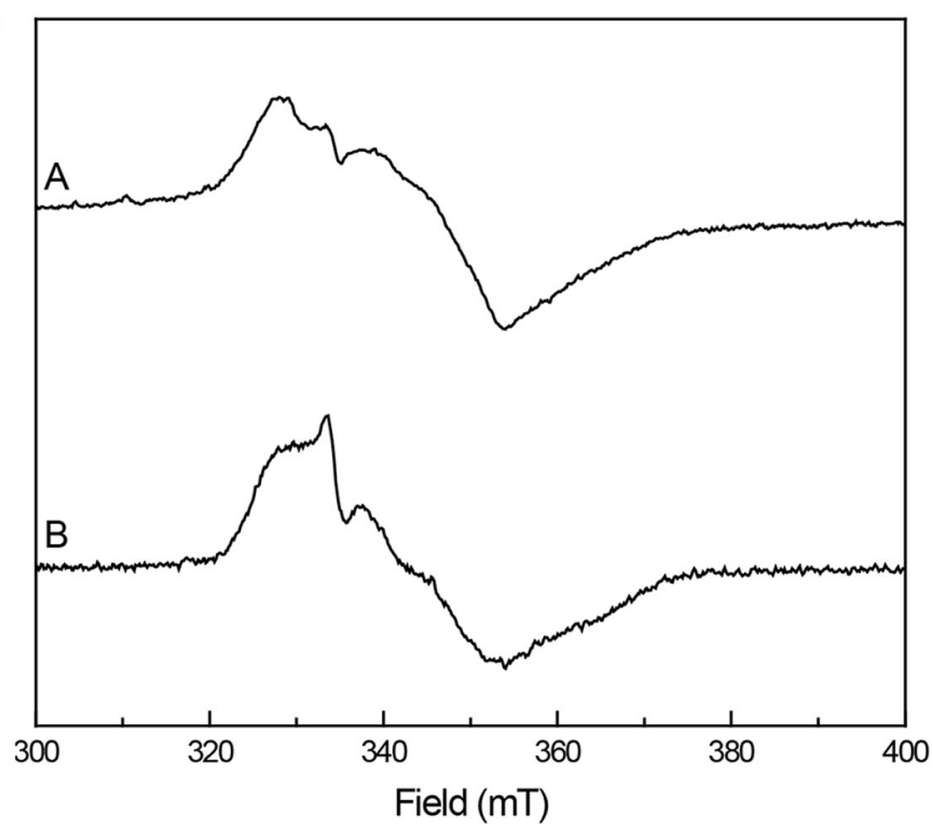

Fig. 3 EPR spectra of IscU2. a Expanded view, trace A: IscU2 ${ }^{C-F e S}(100 \mu M)$ reduced with dithionite, trace B: IscU2 ${ }^{S-F e S}(100 \mu M)$ reduced with dithionite, trace $\mathrm{C}$ : IscU2 $2^{\mathrm{S}-\mathrm{FeS}}(100 \mu \mathrm{M})$ as such. Numbers shown represent $g$ values. b Detailed view, trace A: IscU2 ${ }^{\mathrm{C}-\mathrm{Fe} S}$ reduced with dithionite, trace $\mathrm{B}: \mathrm{Isc} U 2^{\mathrm{S}-\mathrm{FeS}}$ reduced with dithionite

cells compared to lysate from WWM73 cells (Fig. 7c). Overall, these results confirm IscS2 as an in vivo cysteine desulfurase and link IscSU2 to sulfur metabolism in M. acetivorans.

\section{Discussion}

Methanogens are metabolic specialists; all species are dependent on methanogenesis for growth [12]. Methanogenesis has an obligate requirement for $\mathrm{Fe}-\mathrm{S}$ cluster proteins. An understanding of the protein machinery used by methanogens for the de novo synthesis of Fe-S clusters may lead to improved methods to increase or inhibit methanogenesis. The results presented here reveal that $M$. acetivorans harbors functional IscS and $\mathrm{IscU}$, the minimal components of the ISC-type Fe-S cluster biogenesis system, that serve as the general system in numerous bacteria and in mitochondria. It is 


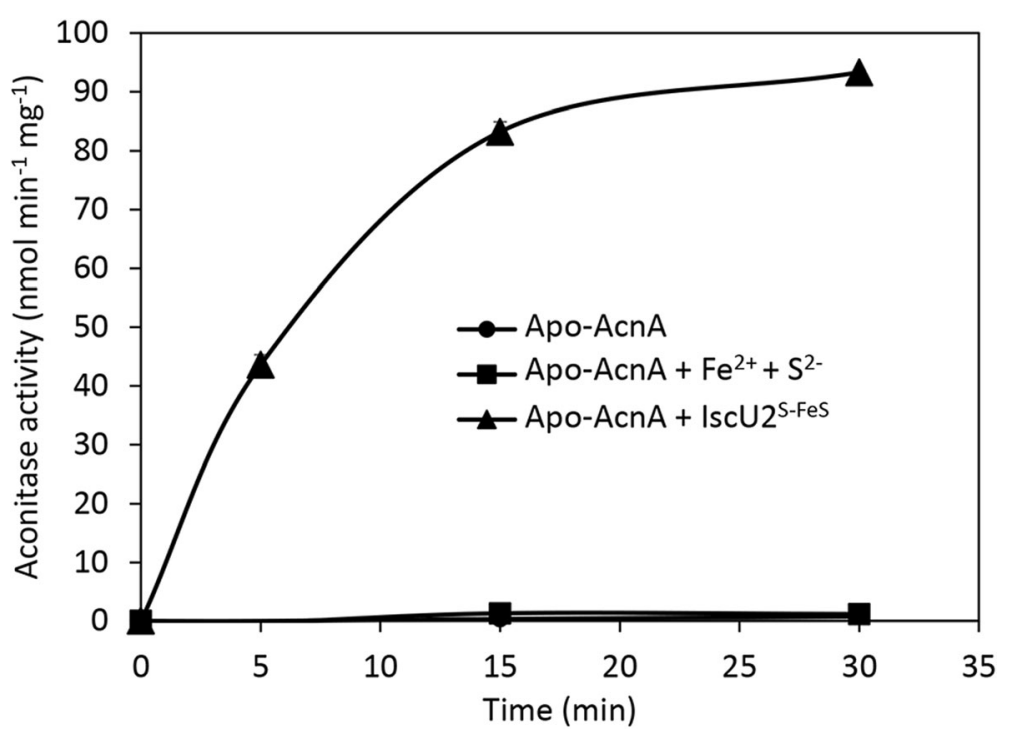

Fig. 4 Reconstitution of apo-AcnA activity by [4Fe-4S]-IscU2. Apo-AcnA (4 $\mu \mathrm{M})$ was incubated with Isc $U 2^{\text {S-FeS }}(40 \mu M)$ or iron $\left(\mathrm{Fe}^{2+}\right)$ and sulfide $\left(\mathrm{S}^{2}\right.$ $\left.{ }^{-}\right)(80 \mu \mathrm{M}$ each) and aconitase activity was measured over time

reasonable to conclude that other methanogens whose sequenced genomes encode IscSU also utilize a minimal ISC system for Fe-S cluster biogenesis.

The absence of IscSU in some methanogens is likely due to physiological differences resulting from environmental constraints. Members of the Methanococcales, Methanopyrales, and some species of Methanobacteriales lack iscSU $[25,43]$. These species appear to lack any cysteine desulfurase, suggesting that cysteine may not serve as the direct sulfur donor for $\mathrm{Fe}-\mathrm{S}$ cluster biogenesis. Indeed, experimental evidence revealed that $M$. maripaludis uses sulfide, instead of cysteine, as the sulfur donor for Fe-S cluster biogenesis [42]. This was the first evidence of a substrate, other than cysteine, serving as the sulfur donor for $\mathrm{Fe}-\mathrm{S}$ cluster biogenesis in any organism. Methanococcus spp. live in sulfide-rich environments and are dependent primarily on sulfide as an exogenous source of sulfur and do not use cysteine [44]. Like all methanogens, M. maripaludis encodes SufBC. It seems likely that methanogen SufBC does not partner with a cysteine desulfurase but receives sulfur from sulfide for the assembly of an Fe-S cluster. The mechanisms and factors involved in directing sulfide to Fe-S cluster biogenesis machinery are unknown in Methanococcus, but presumably involve an unknown protein factor(s) to traffic sulfur from sulfide to SufBC.

Most species of the Methanomicrobia contain at least one copy of iscSU, in addition to $s u f C B$ [25]. All Methanosarcina spp. possess iscSU [43]. Methanosarcina spp. are the most metabolically diverse methanogens capable of producing methane with $\mathrm{H}_{2} / \mathrm{CO}_{2}$, methylated compounds, and acetate. Methanosarcina are one of only two genera capable of metabolizing acetate, which accounts for two-thirds of all biogenic methane produced [12]. Methanosarcina also have the largest genomes and are the most oxygen tolerant methanogens $[26,45]$. Unlike Methanococci, Methanosarcina can use cysteine, in addition to sulfide, as an exogenous sulfur source. The

Table 4 IscU2-dependent recovery of aconitase activity in air-exposed M. acetivorans cell lysates

\begin{tabular}{ll} 
Cell lysate treatment & Aconitase activity $^{\mathrm{a}}$ \\
\hline Anaerobic $\longrightarrow$ anaerobic & $5.2 \pm 0.7$ \\
Aerobic $\longrightarrow$ anaerobic & $\mathrm{BDL}^{\mathrm{b}}$ \\
Aerobic $\longrightarrow$ anaerobic $+\mathrm{IscU} 2$ & $\mathrm{BDL}^{\mathrm{b}}$ \\
Aerobic $\longrightarrow$ anaerobic $+\mathrm{IscU} 2^{\mathrm{S}-\mathrm{Fes}}$ & $1.6 \pm 0.3$ \\
\hline
\end{tabular}

${ }^{a}$ nmol NADPH $\min ^{-1} \mathrm{mg}^{-1}$ protein; Results are means from triplicates \pm 1 standard deviation

${ }^{b}$ Below Detection Limit ( $\geq 0.1 \mathrm{nmol} \mathrm{NADPH} \mathrm{min}^{-1} \mathrm{mg}^{-1}$ protein) 


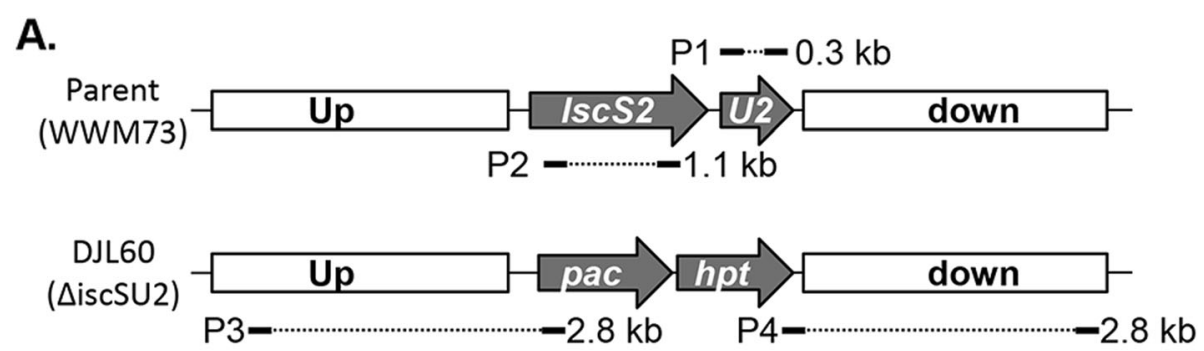

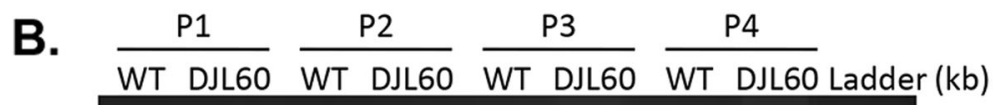

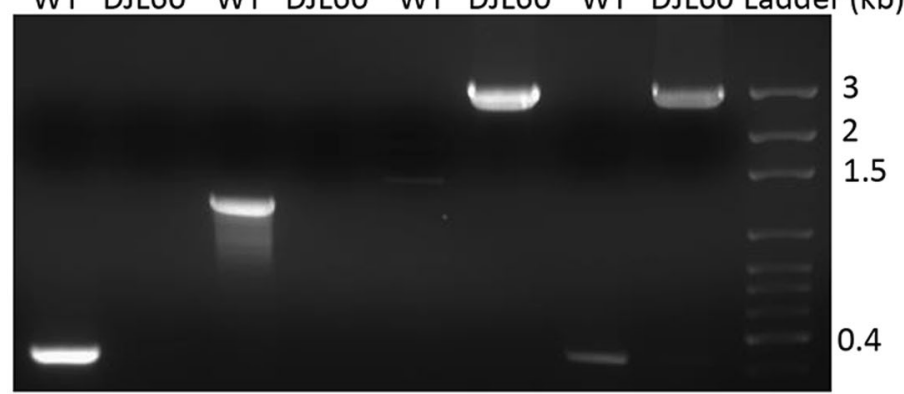

Fig. 5 PCR confirmation of isCSU2 deletion in M. acetivorans strain DJL60. a Schematic showing replacement of iscSU2 with pac-hpt in strain DJL60 and predicted PCR products are indicated by P1-4. b Gel image of products of PCR reactions P1-4 with WWM73 and DJL60 genomic DNA

acquisition of IscSU, in addition to SufBC, may aid in the metabolic diversity and aerotolerance of Methanosarcina by conferring the ability to use cysteine as an exogenous sulfur source and as a direct sulfur source for the biogenesis of $\mathrm{Fe}-\mathrm{S}$ clusters in more oxidizing environments with limited sulfide.

$M$. acetivorans and related Methanosarcinales contain multiple copies of iscSU. M. acetivorans IscSU1-3 may be functionally redundant, which is supported by residual cysteine desulfurase activity and normal Fe-S cluster content in strain DJL60. However, IscS1 and IscU3 lack some of the residues required for the function of $E$. coli IscS and IscU, indicating these orthologs could be non-functional. Alternatively, each ortholog may serve a different function in Fe-S cluster biogenesis. Recently, the structure of a recombinant [2Fe-2S] clustercontaining IscS-IscU complex from Archaeoglobus fulgidus was solved [46]. A. fulgidus is an anaerobic archaeon that is closely related to methanogens. Interestingly, $A$. fulgidus IscS lacks cysteine desulfurase activity due to a substitution of a catalytically essential lysine with aspartate. In the solved structure, A. fulgidus IscS provides a cysteine ligand to the $[2 \mathrm{Fe}-2 \mathrm{~S}]$ cluster in IscU, suggesting it plays a role in cluster assembly as a ligand, but not by providing sulfur [46-48]. Like A. fulgidus IscS, IscS1 lacks the catalytically essential lysine (Fig. S2) indicating it may function as A. fulgidus IscS. Expression of recombinant IscS1 in E. coli led to the formation of inclusion bodies, indicating it may require co-expression with IscU1 for stabilization (data not shown).

Aerobic bacteria and eukaryotes typically have complex ISC and SUF systems that involve several accessory factors, whereas methanogens appear to use only the minimal components, IscSU and SufBC, respectively. It was proposed that the SUF system increased in complexity as additional factors were needed to control iron and sulfur trafficking to synthesize Fe-S clusters in cells that live in more oxidizing environments [25]. The same may be true for the ISC system. For example, the $M$. acetivorans isc gene clusters lack any of the additional genes found in the $E$. coli isc operon, including $h s c A$ and $h s c B$, which are essential to ISC-dependent Fe-S cluster biogenesis in E. coli. HscA and $\mathrm{HscB}$ are chaperones that specifically interact with IscU to accelerate Fe-S cluster transfer to target apo-proteins. HscA specifically binds to the IscU LPPVK motif to elicit conformational changes in IscU dependent on the hydrolysis of ATP [28, 49]. Surprisingly, $M$. acetivorans IscSU1-3 all contain a variant of the LPPVK motif (Table 1), yet the genome of $M$. acetivorans does not encode homologs of HscA or HscB. It is possible that unrelated chaperones fulfill the role of HscA and HscB. However, it was recently shown that several point mutations in IscU suppress the essential role of HscA and HscB in E. coli [50]. Given that $M$. acetivorans cluster-loaded IscU2 rapidly restored the in vitro activity of apo-aconitase in the 


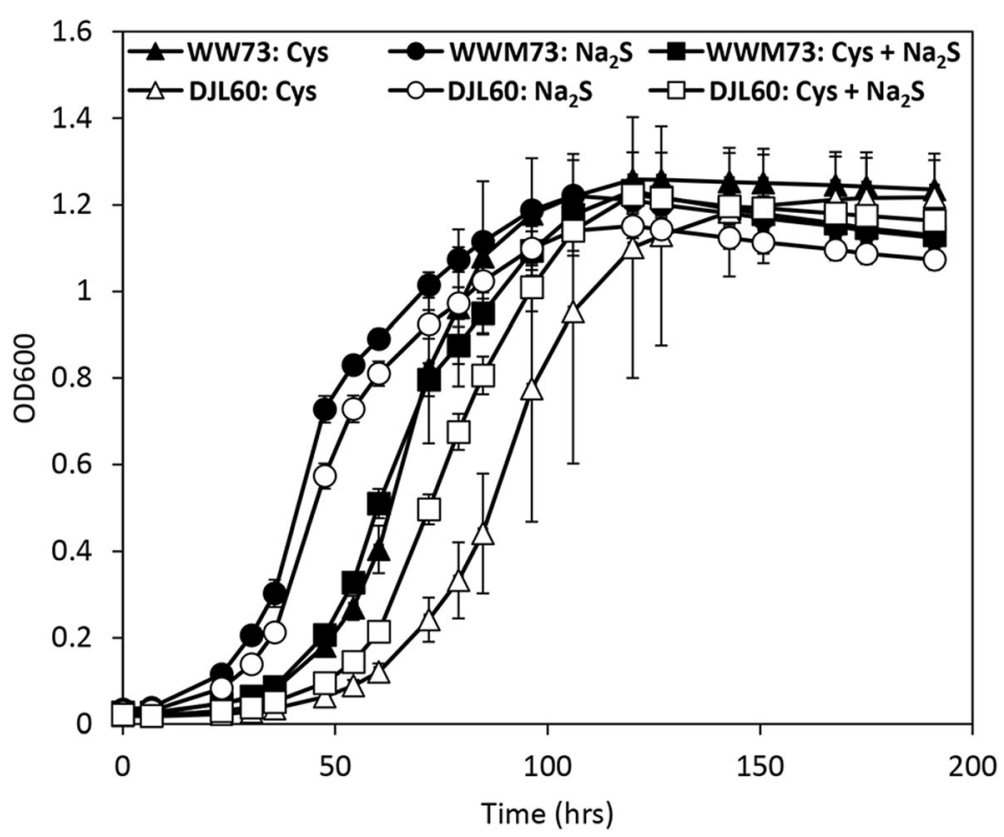

Fig. 6 Growth of M. acetivorans strains WWM73 and DJL60 with different sulfur sources. Each strain was grown in HS DTT medium containing 125 $\mathrm{mM}$ methanol supplemented with $3 \mathrm{mM}$ cysteine (Cys) and/or $3 \mathrm{mM}$ sodium sulfide ( $\mathrm{Na}_{2} \mathrm{~S}$ ). Growth was monitored by the optical density at 600 $\mathrm{nm}\left(\mathrm{OD}_{600}\right)$. Data points are the mean of $n=3$ with error bars \pm STD.

absence of additional factors, it seems more likely that chaperones are not involved in ISC-dependent Fe-S cluster biogenesis in $M$. acetivorans, despite the presence of the LPPVK motif in IscU1-3.

Finally, the results indicate a cysteine-specific function for $M$. acetivorans IscSU2. Deletion of iscSU2 resulted in decreased in vivo cysteine desulfurase activity. Although a decrease in Fe-S cluster content was not observed in strain DJL60 grown with cysteine, it is possible that IscU1 and/or IscU3 serve as Fe-S cluster scaffolds in the absence of IscU2. Cysteine desulfurase serves as the central hub for trafficking sulfur in bacteria and eukaryotes. Importantly, a decrease in the persulfide content of DJL60 cells compared to wild type cells was only observed when cysteine was provided as an exogenous sulfur source, indicating IscS2 participates in trafficking sulfur from cysteine, but is not involved when sulfide is the sole sulfur source. Based on results presented here and with $M$. maripaludis [42, 51], cells of $M$. acetivorans may primarily use IscSU for Fe-S cluster biogenesis and sulfur trafficking when provided cysteine, and primarily use $\mathrm{SufBC}$ for Fe-S cluster biogenesis when cells are provided sulfide.

\section{Conclusions}

This study provides the first experimental evidence that methanogens possess functional components of the ISC system for Fe-S cluster biogenesis. Biochemical analyses demonstrated that $M$. acetivorans IscS is a cysteine desulfurase and that IscU2 is an Fe-S cluster scaffold. Importantly, IscSU2 can provide Fe-S clusters to target apo-proteins. Deletion of iscSU2 revealed that IscSU2 is not essential to $\mathrm{Fe}-\mathrm{S}$ cluster biogenesis in M. acetivorans. However, loss of IscSU2 impacts sulfur metabolism. These results provide new insight into the mechanisms of $\mathrm{Fe}-\mathrm{S}$ cluster biogenesis in methanogens, which may aid in the development of methods to enhance or inhibit methanogenesis, due to the obligate requirement for Fe$S$ proteins.

\section{Methods}

\section{M. acetivorans growth}

$M$. acetivorans strain WWM73 was obtained from Dr. Bill Metcalf [52] and was used as the parent strain for all experiments. All strains of $M$. acetivorans (Table S1) were grown in HS medium containing $125 \mathrm{mM}$ methanol as a carbon and energy source as previously described [53, 54]. Each liter of HS medium contains 23.4 g NaCl, $3.8 \mathrm{~g} \mathrm{NaHCO}_{3}, 1.0 \mathrm{~g} \mathrm{KCl}, 11.0 \mathrm{~g} \mathrm{MgCl}_{2}{ }^{*} 6 \mathrm{H}_{2} \mathrm{O}$, $0.3 \mathrm{~g} \mathrm{CaCl}_{2}{ }^{*} 2 \mathrm{H}_{2} \mathrm{O}, 1.0 \mathrm{~g} \mathrm{NH}_{4} \mathrm{Cl}, 0.5 \mathrm{~g} \mathrm{~L}$-cysteine, $5 \mathrm{~mL}$ of $1 \mathrm{M} \mathrm{KH}_{2} \mathrm{PO}_{4}$ at $\mathrm{pH}=7.4,1 \mathrm{~mL}$ of $0.1 \% \mathrm{w} / \mathrm{v}$ resazurin, $10 \mathrm{~mL}$ of Wolfe's Mineral Solution (supplemented with $0.024 \mathrm{~g} / \mathrm{L} \mathrm{NiCl}{ }_{2}{ }^{*} \mathrm{H}_{2} \mathrm{O}$ in the stock), and $2 \mathrm{~mL}$ of a $5 \mathrm{x}$ concentrated Wolfe's Vitamin Solution [55]. HS medium was made anoxic and dispensed into Balch tubes within an anaerobic chamber (Coy Laboratories) containing $75 \% \mathrm{~N}_{2}, 20 \% \mathrm{CO}_{2}$, and $5 \% \mathrm{H}_{2}$. Standard culture conditions include $0.025 \% \mathrm{w} / \mathrm{v} \mathrm{Na}_{2} \mathrm{~S}^{*} 9 \mathrm{H}_{2} \mathrm{O}$ added from a 
A.

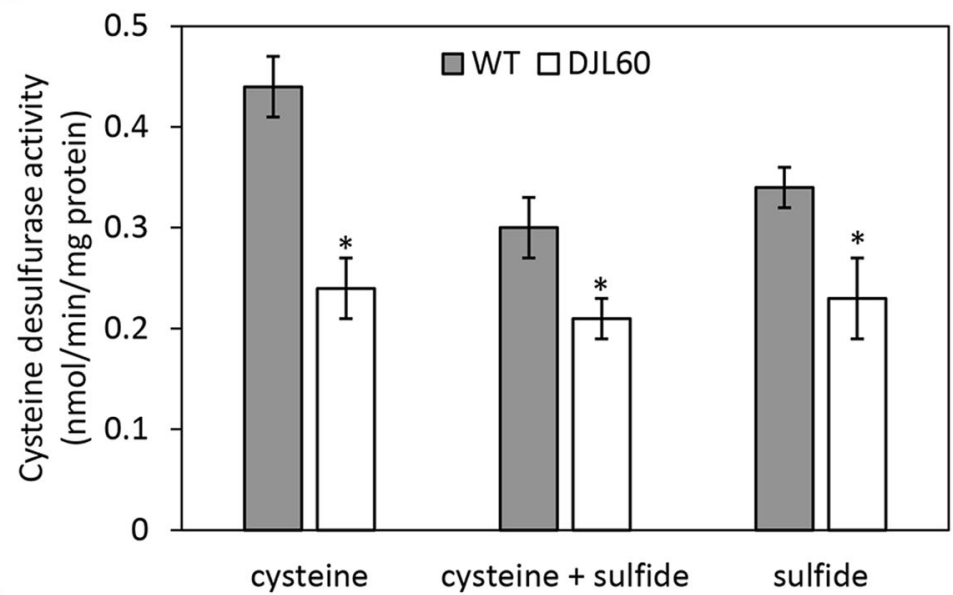

B.

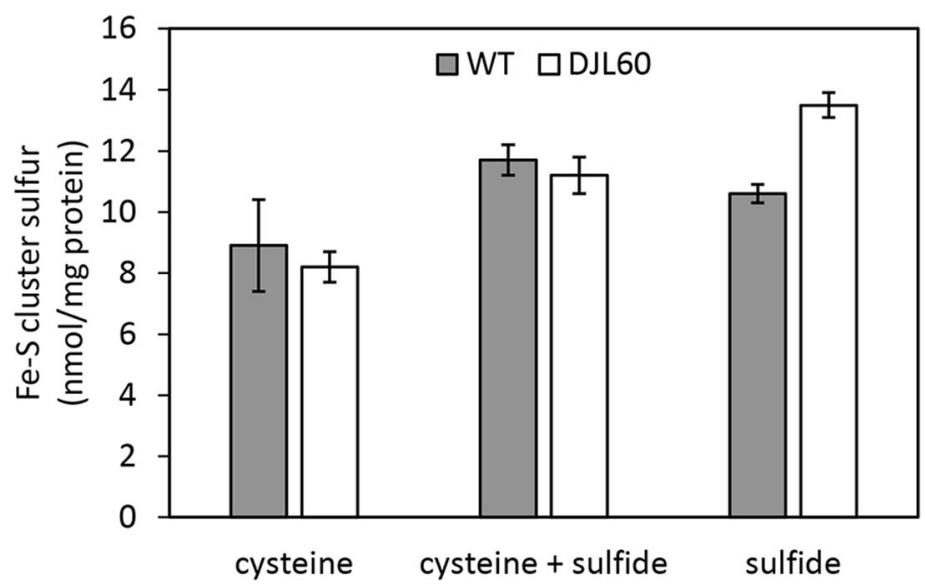

C.

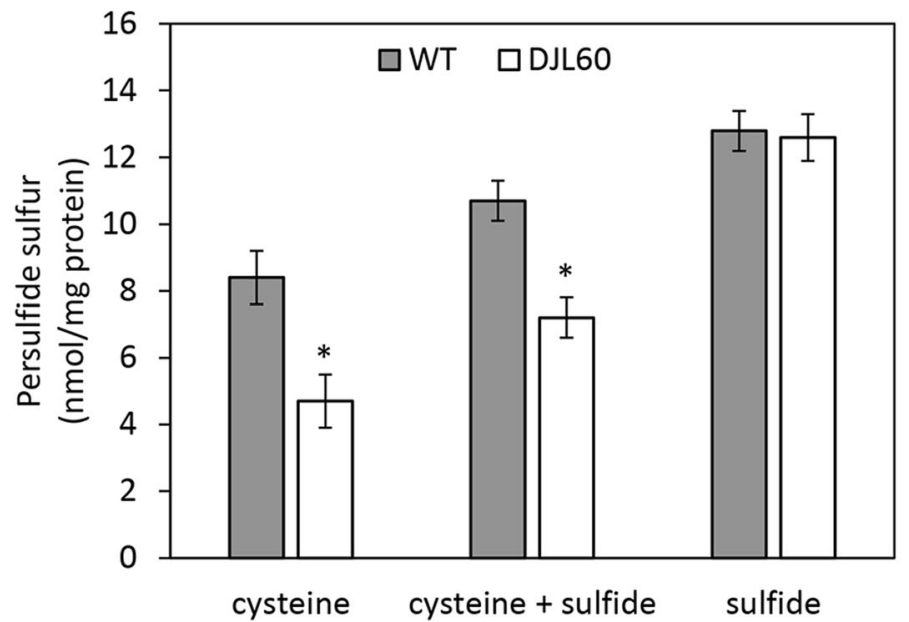

Fig. 7 Cysteine desulfurase activity, Fe-S cluster, and persulfide levels in cell lysates of strains WWM73 and DJL60. Cysteine desulfurase activity (a), Fe-S cluster content (b) and persulfide content (c) were measured as described in methods. Asterisks indicate significant difference between WWM73 and DJL60 lysate, as determined by t-test ( $p<0.02$ for A, $p<0.01$ for C) 
sterile, anoxic stock just prior to inoculation. To examine growth with different sulfur sources, $1.5 \mathrm{mM}$ DTT was added to $\mathrm{HS}$ medium $\left(\mathrm{HS}_{\text {DTT }}\right.$ medium) in lieu of cysteine prior to autoclaving, and $3 \mathrm{mML}$-cysteine and/ or $1 \mathrm{mM}$ sodium sulfide were added from sterile anoxic stock solutions prior to inoculation. Growth was monitored by measuring the optical density at $600 \mathrm{~nm}$ $\left(\mathrm{OD}_{600}\right)$ of the culture tubes using a spectrophotometer (Thermo Fisher, Genesys 10 Bio).

\section{Expression of recombinant $M$. acetivorans IscS2, IscU2, and aconitase in E. coli}

The genes iscS2 (MA2718) and iscU2 (MA2717) were amplified by PCR from Methanosarcina acetivorans genomic DNA isolated from wild-type strain C2A using standard guanidine thiocyanate lysis, protein precipitation, and isopropanol extraction. NdeI and $X$ hoI recognition sites were added at the $5^{\prime}$ and 3 ' ends of the PCR product, respectively. The putative acnA aconitase gene (MA0250) was similarly amplified, but with an NheI site rather than NdeI. All PCR products were generated using Phusion HF polymerase (New England Biolabs) with reagent concentrations per the manufacturer's instructions. Annealing temperatures of $60^{\circ} \mathrm{C}$ for iscS2 and iscu2, and $67^{\circ} \mathrm{C}$ for $a c n A$, were used (primers listed in Table S1). The PCR products were digested with NdeI or NheI and XhoI and ligated using T4 DNA ligase (New England Biolabs) with pET28a that had been similarly digested, resulting in each gene fused to a thrombin-cleavable $\mathrm{His}_{6}$-tag. All enzymes were from New England Biolabs and reactions were carried out per manufacturer's instructions. Sub-cloning efficiency $E$. coli $\mathrm{DH} 5 \alpha$ competent cells (Invitrogen) were transformed with the ligation reactions and cells harboring plasmids with iscU2, iscS2, and acnA were identified by restriction digests and confirmed by DNA sequencing (Eurofins). For expression of each $\mathrm{N}$-terminal $\mathrm{His}_{6}$-tagged recombinant protein, $E$. coli Rosetta (DE3) pLacI was separately transformed with the plasmids containing iscU2 (pDL201), iscS2 (pDL202), and acnA (pDL204).

E. coli Rosetta (DE3) pLacI harboring pDL201, pDL202, or pDL204 were grown in LB medium containing $50 \mu \mathrm{g} / \mathrm{mL}$ kanamycin and $17 \mu \mathrm{g} / \mathrm{mL}$ chloramphenicol with shaking at $37^{\circ} \mathrm{C}$. At an optical density at $600 \mathrm{~nm}$ $\left(\mathrm{OD}_{600}\right)$ of $0.6,0.5 \mathrm{mM}$ IPTG was added, and the temperature was lowered to $25^{\circ} \mathrm{C}$ for the IscS2expression culture or $16^{\circ} \mathrm{C}$ for the IscU2- and AcnAexpression cultures. The AcnA-expression culture was also supplemented with $0.5 \mathrm{M} \mathrm{D}$-sorbitol at induction to inhibit inclusion body formation. After $18 \mathrm{~h}$, cells were harvested by centrifugation and frozen at $-80^{\circ} \mathrm{C}$.

\section{Purification of recombinant proteins}

For purification of IscS2, thawed cells were resuspended in buffer A (20 mM Tris pH 8.0, $500 \mathrm{mM} \mathrm{NaCl}, 10 \%$ glycerol) containing a few crystals of DNase I and approximately $1 \mathrm{mM}$ benzamidine $\mathrm{HCl}$ hydrate. Cells were lysed by two passages through a French pressure cell at $>110$ MPa. Lysates were centrifuged at $41,000 \times g$ and $4{ }^{\circ} \mathrm{C}$ for $35 \mathrm{~min}$. The supernatant was passed through a $0.45 \mu \mathrm{m}$ filter and loaded on a chromatography column containing $5 \mathrm{~mL}$ of $\mathrm{Ni}^{2+}$-agarose resin (Genscript) preequilibrated with $25 \mathrm{~mL}$ of buffer A. The column was sequentially washed with $50 \mathrm{~mL}$ buffer A, $25 \mathrm{~mL}$ buffer A containing $10 \mathrm{mM}$ imidazole, and $25 \mathrm{~mL}$ buffer A. The column was then incubated in $5 \mathrm{~mL}$ buffer A containing $50 \mathrm{U}$ of thrombin (Promega) at $25^{\circ} \mathrm{C}$ for $16 \mathrm{~h}$. Protein was eluted from the column by the addition of $10 \mathrm{~mL}$ of buffer A followed by $10 \mathrm{~mL}$ buffer A containing $250 \mathrm{mM}$ imidazole. Thrombin was removed using a $1 \mathrm{~mL}$ HiPrep benzamidine column (GE Healthcare) following the manufacturer's instructions. Purified IscS2 was exchanged into storage buffer $(50 \mathrm{mM}$ Tris $\mathrm{pH} 8.0,150$ $\mathrm{mM} \mathrm{NaCl}, 10 \%$ glycerol) using a PD-10 column (GE Healthcare) and stored at $-80^{\circ} \mathrm{C}$ until use.

For purification of IscU2, all steps were performed anaerobically under an atmosphere of $95 \% \mathrm{~N}_{2}, 5 \% \mathrm{H}_{2}$ in an anaerobic chamber (Coy Laboratories). Thawed cells were resuspended in buffer B (20 mM Tris pH 8.0, $2 \mathrm{M}$ $\mathrm{NaCl}, 10 \%$ glycerol) containing a few crystals of DNase I and benzamidine $\mathrm{HCl}$ hydrate. Cells were lysed by two passages through a French pressure cell at $>110 \mathrm{MPa}$. Lysates were centrifuged at $41,000 \times \mathrm{g}$ and $4{ }^{\circ} \mathrm{C}$ for 35 min. The supernatant was passed through a $0.45 \mu \mathrm{m}$ filter and loaded on a $5 \mathrm{~mL} \mathrm{Ni}^{2+}$-agarose resin chromatography column pre-equilibrated with $25 \mathrm{~mL}$ of buffer B. The column was sequentially washed with $50 \mathrm{~mL}$ buffer B, $25 \mathrm{~mL}$ buffer B containing $10 \mathrm{mM}$ imidazole, $25 \mathrm{~mL}$ buffer $\mathrm{B}$, and $25 \mathrm{~mL}$ buffer $\mathrm{A}$. The column was then incubated in $5 \mathrm{~mL}$ buffer A containing $50 \mathrm{U}$ of thrombin at $25^{\circ} \mathrm{C}$ for $16 \mathrm{~h}$. Protein was eluted from the column by the addition of $10 \mathrm{~mL}$ of buffer A followed by $10 \mathrm{~mL}$ buffer A containing $250 \mathrm{mM}$ imidazole. Thrombin was removed using a $1 \mathrm{~mL}$ HiPrep benzamidine column (GE Healthcare) following the manufacturer's instructions. The partially purified protein was loaded onto a HiPrep 16/60 Sephacryl S-200 gel filtration column using a Biologic LP system (Bio-Rad) housed within the anaerobic chamber. The column was run at a flow rate of $0.5 \mathrm{ml} \mathrm{min}^{-1}$ with $50 \mathrm{mM}$ Tris $\mathrm{pH} 8.0$, $150 \mathrm{mM} \mathrm{NaCl}, 10 \%$ glycerol, $2 \mathrm{mM}$ DTT. Fractions containing only IscU2, as determined by SDS-PAGE, were pooled, concentrated, and desalted into storage buffer $(50 \mathrm{mM}$ Tris pH 8.0, $150 \mathrm{mM} \mathrm{NaCl}, 10 \%$ glycerol) using a PD-10 column. Purified IscU2 was stored under $\mathrm{N}_{2}$ at $-80^{\circ} \mathrm{C}$. 
For the purification of AcnA all steps were performed anaerobically under an atmosphere of $95 \% \mathrm{~N}_{2}, 5 \% \mathrm{H}_{2}$ in an anaerobic chamber (Coy Laboratories). Thawed cells were resuspended in buffer $\mathrm{C}(20 \mathrm{mM}$ Tris, $\mathrm{pH} 8.0,500$ $\mathrm{mM} \mathrm{NaCl}$ ) containing a few crystals of DNase I and benzamidine $\mathrm{HCl}$ hydrate. Cells were lysed by three passages through a French pressure cell at $>110 \mathrm{MPa}$. Lysates were centrifuged at $41,000 \times g$ and $4{ }^{\circ} \mathrm{C}$ for $35 \mathrm{~min}$. The supernatant was passed through a $0.45 \mu \mathrm{m}$ filter and loaded on a $5 \mathrm{ml} \mathrm{Ni}^{2+}$-agarose resin chromatography column preequilibrated with $25 \mathrm{ml}$ of buffer $\mathrm{C}$. The column was sequentially washed with $50 \mathrm{~mL}$ buffer $\mathrm{C}, 25 \mathrm{~mL}$ buffer $\mathrm{C}$ containing $50 \mathrm{mM}$ imidazole, and $25 \mathrm{~mL}$ buffer $\mathrm{C}$. The column was then incubated in $5 \mathrm{~mL}$ Buffer $\mathrm{C}$ containing $50 \mathrm{U}$ of thrombin (Promega) at $25^{\circ} \mathrm{C}$ for $16 \mathrm{~h}$. Protein was eluted from the column by the addition of $10 \mathrm{~mL}$ of buffer C containing $75 \mathrm{mM}$ imidazole. The partially purified protein was loaded onto a HiPrep 16/60 Sephacryl S-200 gel filtration column and eluted under the same conditions as for IscU2. Fractions containing AcnA, as determined by SDS-PAGE, were pooled, concentrated, and bufferexchanged into buffer D (20 mM Bis-Tris, pH 6.8). A 1 mL HiTrap Q XL ion exchange column (GE Healthcare) was pre-equilibrated with buffer $\mathrm{D}$ and loaded with partially purified AcnA. The column was washed with $20 \mathrm{~mL}$ of buffer $\mathrm{C}$ containing $200 \mathrm{mM} \mathrm{NaCl}$, then with buffer $\mathrm{C}$ containing stepwise-increasing concentrations of $\mathrm{NaCl}$ (220-300 $\mathrm{mM}$ in $20 \mathrm{mM}$ increments). The flow rate was $1 \mathrm{~mL} \mathrm{~min}{ }^{-1}$. Fractions containing only AcnA, as determined by SDS-PAGE, were pooled, concentrated, and desalted into storage buffer (50 mM Tris pH 8.0, $150 \mathrm{mM}$ $\mathrm{NaCl}$ ) using a PD-10 column. Purified AcnA was stored under $\mathrm{N}_{2}$ at $-80^{\circ} \mathrm{C}$.

Recombinant IscS2, IscU2, and AcnA were each separately purified at least twice, and similar results were observed with each preparation. Results are included from a single preparation unless noted otherwise. All protein concentrations were determined by the Bradford assay [1] using bovine serum albumin as a standard. Protein purity was analyzed by SDS-PAGE using a 10\% gel for AcnA, $12 \%$ gel for IscS2, and 15\% gel for IscU2. A Broad Range $(10-230 \mathrm{kDa})$ prestained protein ladder (New England Biolabs) was used to approximate the molecular weight of each protein. SDS-PAGE gels were stained with Coomassie Brilliant Blue solution, then destained prior to imaging.

\section{Reconstitution of IscS2 with PLP}

IscS2 $(150 \mu \mathrm{M})$ was incubated with $3 \mathrm{mM}$ PLP in $50 \mathrm{mM}$ Tris $\mathrm{pH} 7.2,150 \mathrm{mM} \mathrm{NaCl}$, at $25^{\circ} \mathrm{C}$ for $3 \mathrm{~h}$. Unbound PLP was removed from the IscS2/PLP mix by desalting into storage buffer $(50 \mathrm{mM}$ Tris $\mathrm{pH} 8.0,150 \mathrm{mM} \mathrm{NaCl}$, $10 \%$ glycerol) using a PD-10 column. This sample of IscS2 was designated IscS2 ${ }^{\text {PLP }}$.

\section{IscU2 Fe-S cluster reconstitution}

Two methods were used to examine IscsU2 Fe-S cluster reconstitution. All steps were performed inside an anaerobic chamber. Chemical reconstitution was carried out during a purification of IscU2. After removal of thrombin, partially pure IscU2 ( $33 \mathrm{mg}$ of protein) was diluted in $50 \mathrm{~mL}$ of $50 \mathrm{mM}$ Tris pH 8.0, $150 \mathrm{mM} \mathrm{NaCl}, 10 \%$ glycerol, followed by the addition of $2 \mathrm{mM} \beta$-mercaptoethanol, $138 \mu \mathrm{M}$ ferrous ammonium sulfate, and $138 \mu \mathrm{M}$ sodium sulfide. The reaction mix was incubated at $4{ }^{\circ} \mathrm{C}$ for $16 \mathrm{~h}$ and then concentrated to $2.5 \mathrm{~mL}$ using a stirred-cell concentrator ( $5 \mathrm{kDa}$ MW cutoff). IscU2 was purified from the reaction mix by size-exclusion chromatography as described above and designated IscU2 ${ }^{\mathrm{C}-\mathrm{FeS}}$. IscS2-dependent $\mathrm{Fe}-\mathrm{S}$ cluster reconstitution of IscU2 was performed by incubating $160 \mu \mathrm{M}$ IscU2 in $100 \mathrm{mM}$ Tris $\mathrm{pH} 7.4$ containing $8 \mu \mathrm{M}$ IscS2, $2 \mathrm{mM}$ DTT, $1.6 \mathrm{mM}$ ferrous ammonium sulfate, and $1.6 \mathrm{mM} \mathrm{L}$-cysteine for $1 \mathrm{~h}$ at $25^{\circ} \mathrm{C}$. The reaction mix was desalted into storage buffer using a PD-10 column, and aliquots were stored under $\mathrm{N}_{2}$ at $-80^{\circ} \mathrm{C}$.

\section{Determination of the oligomeric state of IscS2 and IscU2}

The oligomeric state of IscS2 and IscU2 was determined by size-exclusion chromatography using a HiPrep 16/60 Sephacryl S-200 gel filtration column. The column was run at a flow rate of $0.5 \mathrm{ml} \mathrm{min}^{-1}$ with $50 \mathrm{mM}$ Tris $\mathrm{pH} 8.0,150 \mathrm{mM}$ $\mathrm{NaCl}, 10 \%$ glycerol, $2 \mathrm{mM}$ DTT, and calibrated with standard proteins (Low molecular weight standards, SigmaAldrich): $\beta$-amylase $(200 \mathrm{kDa})$, alcohol dehydrogenase $(150$ $\mathrm{kDa})$, bovine serum albumin $(66 \mathrm{kDa})$, carbonic anhydrase $(29 \mathrm{kDa})$, and cytochrome $c(12.4 \mathrm{kDa})$.

\section{Cysteine desulfurase assay}

Cysteine desulfurase activity was determined by measuring production of sulfide from L-cysteine using the methylene blue method [56]. Assays were performed with $5 \mu \mathrm{M}$ IscS2 in $50 \mathrm{mM}$ Tris $\mathrm{pH} 7.5,1 \mathrm{mM}$ DTT in the presence or absence of $50 \mu \mathrm{M}$ PLP. Reactions were initiated by the addition of $1 \mathrm{mML}$-cysteine in a total reaction of $1 \mathrm{~mL}$ and were incubated at $25^{\circ} \mathrm{C}$ for $20 \mathrm{~min}$ in sealed vials. The reaction was stopped after $20 \mathrm{~min}$ by the addition of zinc acetate and sodium hydroxide. The mixtures were developed, and absorbance measured at $670 \mathrm{~nm}$.

Similar assays were performed on $M$. acetivorans WWM73 cell-free lysates. Cell cultures were grown to an $\mathrm{OD}_{600}$ between $0.6-0.8$, and cells were pelleted in sealed anoxic bottles at $11,000 \times \mathrm{g}$ for $10 \mathrm{~min}$ at $4{ }^{\circ} \mathrm{C}$. Cell pellets were resuspended in $50 \mathrm{mM}$ Tris $\mathrm{pH} 8.0$ containing, $1 \mathrm{mM}$ benzamidine, $1 \mathrm{mM}$ phenylmethylsulfonyl fluoride, transferred to vials, and stored under $\mathrm{N}_{2}$ at $-80^{\circ} \mathrm{C}$ until use. Cells were lysed by sonication in an anaerobic chamber, centrifuged at $16,000 \times g$ for $10 \mathrm{~min}$., and the supernatant saved. L-cysteine desulfurase activity was measured using crude lysate $(0.16$ to $0.34 \mathrm{mg})$ as 
described above. Reaction mixtures were incubated at $37^{\circ} \mathrm{C}$ for $45 \mathrm{~min}$ before termination by adding $100 \mu \mathrm{L} 20 \mathrm{mM} \mathrm{N}, \mathrm{N}$ Dimethyl-p-phenylenediamine dihydrochloride in $7.3 \mathrm{M} \mathrm{HCl}$ and $100 \mu \mathrm{L} 30 \mathrm{mM} \mathrm{FeCl}_{3}$ in $1.2 \mathrm{M} \mathrm{HCl}$ using gas-tight syringes. Color developed over $30 \mathrm{~min}$, then solutions were quickly vented, spun at 16,000 $\mathrm{g}$, and absorbances read at $670 \mathrm{~nm}$.

\section{Spectroscopy}

UV-visible spectra of IscS2 and IscU2 were recorded using a Cary 60 spectrophotometer (Agilent Technologies) housed within an anaerobic chamber. CW EPR spectra were measured at X-band $(9 \mathrm{GHz})$ frequency on a Bruker EMX spectrometer, fitted with the ER-4119-HS high sensitivity perpendicular-mode cavity. The Oxford Instrument ESR 900 flow cryostat in combination with the ITC4 temperature controller was used for measurements in the $4 \mathrm{~K}$ to $300 \mathrm{~K}$ range using a helium flow. All spectra were recorded with a field modulation frequency of $100 \mathrm{kHz}$, modulation amplitude of $0.6 \mathrm{mT}$, and a frequency of $9.386 \mathrm{GHz}$. Samplespecific conditions are indicated in the figure legends.

\section{Determination of Fe-S cluster and persulfide content in lysate}

Acid-labile and persulfide (sulfane) sulfur concentrations were determined in cell-free lysates from strains WWM73 and DJL60 grown on different sulfur sources using the methylene blue method as above. Cell-free lysate was prepared as described above for L-cysteine desulfurase assays. Soluble protein $(0.195$ to $0.335 \mathrm{mg}$ ) were directly assayed by the methylene blue method (acid-labile sulfur) or were incubated at $37^{\circ} \mathrm{C}$ with 1 $\mathrm{mM}$ DTT for $60 \mathrm{~min}$ in sealed vials prior to sulfide determination to assay reductant-labile (persulfide) sulfur. The persulfide concentration was determined by subtracting the amount of acid-labile sulfur determined in the absence of DTT. Control samples containing DTT without lysate did not produce detectable sulfur.

\section{Aconitase reconstitution assays}

AcnA $(56 \mu \mathrm{M})$ was rendered to the apo-form by anaerobic incubation on ice with $50 \mathrm{M}$ excess $(2.8 \mathrm{mM})$ EDTA, $20 \mathrm{M}$ excess $(1.12 \mathrm{mM})$ potassium ferricyanide in $50 \mathrm{mM}$ Tris $\mathrm{pH} 7.2,150$ $\mathrm{mM} \mathrm{NaCl}$. After $15 \mathrm{~min}$ of incubation, apo-AcnA was desalted using a NAP5 column (GE Healthcare) and stored under $\mathrm{N}_{2}$ at $-80^{\circ} \mathrm{C}$ in $50 \mathrm{mM}$ Tris $\mathrm{pH} 7.2,150 \mathrm{mM} \mathrm{NaCl}$ until use.

Apo-AcnA was mixed with a 10-fold molar excess of IscU2 ${ }^{\text {S-FeS }}$ (or with a 40-fold molar excess of ferrous ammonium sulfate and sodium sulfide, or buffer in control reactions) in $50 \mathrm{mM}$ Tris pH 7.2, $150 \mathrm{mM} \mathrm{NaCl}, 1 \mathrm{mM}$ DTT and allowed to incubate at room temperature in a sealed anaerobic chamber for up to thirty minutes. Samples of these cluster-transfer (or control) incubations were added to activity assay mixtures to achieve final concentrations of $50 \mathrm{mM}$ Tris $\mathrm{pH} 8,0.8 \mu \mathrm{M}$ AcnA, $20 \mathrm{mM}$ sodium citrate, $250 \mu \mathrm{M}$
$\mathrm{NADP}^{+}, 1 \mathrm{mM}$ manganese sulfate, and 0.5 units $/ \mathrm{mL}$ porcine isocitrate dehydrogenase ( $\mathrm{ICDH})$. The assay mixtures were immediately read anaerobically for absorbance at $340 \mathrm{~nm}$ over $8 \mathrm{~min}$ in a spectrophotometer. Samples of AcnA that had incubated with IscU2 $2^{\mathrm{S}-\mathrm{FeS}}$ (or controls) for $5 \mathrm{~min}, 15$ $\mathrm{min}$, and $30 \mathrm{~min}$ were analyzed.

Aconitase activity was also measured in $M$. acetivorans WWM73 cell lysates, as above. Lysate supernatant was used in place of aconitase. Lysate was divided into aliquots and incubated for 3 hours at room temperature, with some maintained in an anaerobic chamber while another aliquot was exposed to ambient oxygen. After 3 hours, the aerobically exposed sample was quickly made anoxic again by vacuuming and purging with nitrogen. Aliquots of the samples were incubated with IscU2 or IscU2 ${ }^{\mathrm{S}-\mathrm{FeS}}$, or controls, in $50 \mathrm{mM}$ Tris $\mathrm{pH} 7.2,150 \mathrm{mM} \mathrm{NaCl}$ for $15 \mathrm{~min}$, then aconitase/ICDH assays were performed as above.

\section{Generation of a $M$. acetivorans iscSU2 deletion mutant}

The pseudo-wildtype parent strain, WWM73, and plasmid vectors for genetic manipulation were generously provided by Prof. William Metcalf from the University of Illinois, and are listed in Table S1. The iscSU2 deletion mutant was generated using pJK301 and methods similar to those previously described [57]. Briefly, homologous regions upstream (US) and downstream (DS) of iscS2U2 were amplified by PCR, using primers containing ApaI and HindIII recognition sites for the US region and BamHI, and SpeI for the DS region. Each PCR product was digested with the appropriate restriction enzymes and sequentially ligated into similarly digested pJK301. Restriction digestion, ligation, and transformation were all carried out as described above. The complete iscS2U2 knockout plasmid (pDL214) was confirmed by DNA sequencing (Eurofins). Unless otherwise noted, all procedures described below were performed in an anerobic chamber (Coy Laboratories). M. acetivorans strain WWM73 was transformed with approximately $2 \mu \mathrm{g}$ of pDL214 linearized by digestion with NotI, using the liposomal transfection method as previously described [58]. Transformants were selected by spread plating on HS agar plates $(0.8 \% \mathrm{w} / \mathrm{v}$ noble agar) containing $125 \mathrm{mM}$ methanol and $2 \mu \mathrm{g} / \mathrm{mL}$ puromycin. The plates were placed in a canning jar along with a vial containing $2 \mathrm{ml}$ of $2.5 \%$ sodium sulfide. The jar was sealed and incubated at $35^{\circ} \mathrm{C}$ in a standard incubator. Well-isolated colonies were inoculated into HS medium supplemented with $125 \mathrm{mM}$ methanol and $2 \mu \mathrm{g} / \mathrm{mL}$ puromycin. Deletion of iscS2U2 and replacement with the pac-hpt cassette from the pJK301 was confirmed in selected transformants by sequencing PCR products generated with primers listed in Table S1 and genomic DNA isolated from transformants. Once confirmed, the iscSU2 deletion strain was designated as $M$. acetivorans strain DJL60. 


\section{Supplementary information}

Supplementary information accompanies this paper at https://doi.org/10. 1186/s12866-020-02014-z.

Additional file $\mathbf{1}$ Table S1. Strains, plasmids, and primers used in this study. Fig. S1. Arrangement of the gene clusters containing iscSand isc Uin E. coli and M. acetivorans C2A. Other predicted gene functions: MA0806, conserved hypothetical protein; MA0809, DrsEsuperfamily protein; MA0810, SirA-like protein; MA0811, histidine triad protein; MA2714, homoserine O-acetyltransferase; MA2715, O-acetylhomoserine (thiol)-lyase; MA2716, quinolinatesynthetase A; MA2719, helix-turn-helix XRE-family like protein; MA3262, LrgBsuperfamily protein; MA3263, LrgAsuperfamily protein. Fig. S2. Amino acid sequence alignment of M. acetivoransIscS1-3 with IscSfrom Escherichia coli and Archaeoglobusfulgidus. The active site residues in E. coli IscSare red and boxed. The PLP binding residues in E. coli IscSare green. Ec: E. coli; Af: A. fulgidus. Fig. S3. Amino acid sequence alignment of $M$. acetivoransIscU1-3 with IscUfrom Escherichia coli and Archaeoglobusfulgidus. The Fe-S cluster binding residues in E. coli IscUare red, and the conserved aspartate and histidine are green. The HscA-interacting region is boxed. Ec: E. coli; Af: A. fulgidus. Fig. S4.

Characterization of recombinant $M$. acetivorans aconitase (AcnA).A) SDSPAGE analysis of purified recombinant AcnA. B) UV-visible spectrum of purified AcnAafter in vitro reconstitution with iron and sulfur.

\section{Abbreviations}

ICDH: Isocitrate dehydrogenase; AcnA: Aconitase; Fe-S: Iron-sulfur; HS: Highsalt; DTT: Dithiothreitol; PLP: Pyridoxal 5'- phosphate

\section{Acknowledgments}

Not applicable.

\section{Authors' contributions}

TMD performed most of the experimental work. FHL assisted in performing experiments and analyzing data. DP and ECD performed EPR and analyzed data. DJL analyzed data, interpreted results, and wrote final manuscript with TMD. The authors read and approved the final manuscript.

\section{Funding}

Genetic analysis and initial biochemical experimentation was supported in part by NSF grant number MCB1817819 (DJL), NASA Exobiology grant number NNX12AR60G (DJL and ECD), and the Arkansas Biosciences Institute (DJL), the major research component of the Arkansas Tobacco Settlement Proceeds Act of 2000. Biophysical experimentation and lysate analysis was supported by DOE Biosciences grant number DE-SC0019226 (DJL and ECD). The funding agencies were not involved in the design of the study, the analysis and interpretation of data, or in the writing of the manuscript.

\section{Availability of data and materials}

The datasets and/or analyzed during the current study are available from the corresponding author on reasonable request.

\section{Ethics approval and consent to participate}

Not applicable.

\section{Consent for publication}

Not applicable.

\section{Competing interests}

The authors declare that they have no competing interests.

\section{Author details}

'Department of Biological Sciences, University of Arkansas-Fayetteville, Fayetteville, AR 72701, USA. ²Department of Biochemistry and Molecular Biology, The Pennsylvania State University, University Park, PA 16802, USA. ${ }^{3}$ Department of Chemistry and Biochemistry, Auburn University, Auburn, AL 36849, USA.
Received: 6 July 2020 Accepted: 15 October 2020

Published online: 23 October 2020

\section{References}

1. Johnson DC, Dean DR, Smith AD, Johnson MK. Structure, function, and formation of biological iron-sulfur clusters. Annu Rev Biochem. 2005;74:247-81.

2. Bandyopadhyay A, Stockel J, Min H, Sherman LA, Pakrasi HB. High rates of photobiological $\mathrm{H} 2$ production by a cyanobacterium under aerobic conditions. Nat Commun. 2010;1:139.

3. Chandrayan SK, McTernan PM, Hopkins RC, Sun J, Jenney FE Jr, Adams MW. Engineering hyperthermophilic archaeon Pyrococcus furiosus to overproduce its cytoplasmic [NiFe]-hydrogenase. J Biol Chem. 2012;287: 3257-64.

4. Sousa FL, Thiergart T, Landan G, Nelson-Sathi S, Pereira IA, Allen JF, et al. Early bioenergetic evolution. Philos Trans R Soc Lond B Biol Sci. 2013;368: 20130088

5. Peters JW, Fisher K, Dean DR. Nitrogenase structure and function: a biochemical-genetic perspective. Annu Rev Microbiol. 1995;49:335-66.

6. Peters JW, Schut GJ, Boyd ES, Mulder DW, Shepard EM, Broderick JB, et al. [FeFe]- and [NiFe]-hydrogenase diversity, mechanism, and maturation. Biochim Biophys Acta. 2015;1853:1350-69.

7. Ragsdale SW. Nickel containing CO dehydrogenases and hydrogenases. Subcell Biochem. 2000;35:487-518.

8. Hu Y, Ribbe MW. Biosynthesis of the Metalloclusters of Nitrogenases. Annu Rev Biochem. 2016;85:455-83.

9. Major TA, Burd $H$, Whitman WB. Abundance of $4 \mathrm{Fe}-4 \mathrm{~S}$ motifs in the genomes of methanogens and other prokaryotes. FEMS Microbiol Lett. 2004;239:117-23.

10. Ferry JG. Enzymology of one-carbon metabolism in methanogenic pathways. FEMS Microbiol Rev. 1999:23:13-38.

11. Thauer RK. The Wolfe cycle comes full circle. Proc Natl Acad Sci U S A. 2012; 109:15084-5.

12. Thauer RK, Kaster AK, Seedorf H, Buckel W, Hedderich R. Methanogenic archaea: ecologically relevant differences in energy conservation. Nat Rev Microbiol. 2008:6:579-91.

13. Costa KC, Wong PM, Wang T, Lie TJ, Dodsworth JA, Swanson I, et al. Protein complexing in a methanogen suggests electron bifurcation and electron delivery from formate to heterodisulfide reductase. Proc Natl Acad Sci U S A. 2010:107:11050-5.

14. Hedderich R, Hamann N, Bennati M. Heterodisulfide reductase from methanogenic archaea: a new catalytic role for an iron-sulfur cluster. Biol Chem. 2005;386:961-70.

15. Wagner T, Ermler U, Shima S. The methanogenic CO2 reducing-and-fixing enzyme is bifunctional and contains 46 [4Fe-4S] clusters. Science. 2016;354: $114-7$.

16. Lessner FH, Jennings ME, Hirata A, Duin EC, Lessner DJ. Subunit D of RNA polymerase from Methanosarcina acetivorans contains two oxygen-labile [4Fe-4S] clusters: implications for oxidant-dependent regulation of transcription. J Biol Chem. 2012;287:18510-23.

17. Boyd ES, Hamilton TL, Peters JW. An alternative path for the evolution of biological nitrogen fixation. Front Microbiol. 2011;2:205

18. Dos Santos PC, Fang Z, Mason SW, Setubal JC, Dixon R. Distribution of nitrogen fixation and nitrogenase-like sequences amongst microbial genomes. BMC Genomics. 2012;13:162.

19. Dekas AE, Poretsky RS, Orphan VJ. Deep-sea archaea fix and share nitrogen in methane-consuming microbial consortia. Science. 2009:326:422-6.

20. Ayala-Castro C, Saini A, Outten FW. Fe-S cluster assembly pathways in bacteria. Microbiol Mole Biol Rev. 2008:72:110-25 table of contents.

21. Couturier J, Touraine B, Briat JF, Gaymard F, Rouhier N. The iron-sulfur cluster assembly machineries in plants: current knowledge and open questions. Front Plant Sci. 2013:4:259.

22. Fontecave $\mathrm{M}$, Ollagnier-de-Choudens $\mathrm{S}$. Iron-sulfur cluster biosynthesis in bacteria: mechanisms of cluster assembly and transfer. Arch Biochem Biophys. 2008;474:226-37.

23. Roche B, Aussel L, Ezraty B, Mandin P, Py B, Barras F. Iron/sulfur proteins biogenesis in prokaryotes: formation, regulation and diversity. Biochim Biophys Acta. 2013;1827:455-69.

24. Blanc B, Gerez C, Ollagnier de Choudens S. Assembly of Fe/S proteins in bacterial systems: biochemistry of the bacterial ISC system. Biochim Biophys Acta. 2014;1853:1436-47. 
25. Boyd ES, Thomas KM, Dai Y, Boyd JM, Outten FW. Interplay between oxygen and Fe-S cluster biogenesis: insights from the Suf pathway. Biochemistry. 2014,53:5834-47

26. Galagan JE, Nusbaum C, Roy A, Endrizzi MG, Macdonald P, FitzHugh W, et al. The genome of Methanosarcina acetivorans reveals extensive metabolic and physiological diversity. Genome Res. 2002;12:532-42.

27. Mihara H, Esaki N. Bacterial cysteine desulfurases: their function and mechanisms. Appl Microbiol Biotechnol. 2002;60:12-23.

28. Bonomi F, lametti S, Morleo A, Ta D, Vickery LE. Facilitated transfer of IscU[2Fe2S] clusters by chaperone-mediated ligand exchange. Biochemistry. 2011;50:9641-50.

29. Fournier GP, Gogarten JP. Evolution of acetoclastic methanogenesis in Methanosarcina via horizontal gene transfer from cellulolytic clostridia. J Bacteriol. 2008;190:1124-7.

30. Lessner DJ, Li L, Li Q, Rejtar T, Andreev VP, Reichlen M, et al. An unconventional pathway for reduction of $\mathrm{CO} 2$ to methane in CO-grown Methanosarcina acetivorans revealed by proteomics. Proc Natl Acad Sci U S A. 2006;103:17921-6.

31. Li L, Li Q, Rohlin L, Kim U, Salmon K, Rejtar T, et al. Quantitative proteomic and microarray analysis of the archaeon Methanosarcina acetivorans grown with acetate versus methanol. J Proteome Res. 2007:6:759-71.

32. Li Q, Li L, Rejtar T, Karger BL, Ferry JG. Proteome of Methanosarcina acetivorans part II: comparison of protein levels in acetate- and methanolgrown cells. J Proteome Res. 2005;4:129-35.

33. Li Q, Li L, Rejtar T, Karger BL, Ferry JG. Proteome of Methanosarcina acetivorans part I: an expanded view of the biology of the cell. J Proteome Res. 2005;4:112-28.

34. Zheng L, White RH, Cash VL, Jack RF, Dean DR. Cysteine desulfurase activity indicates a role for NIFS in metallocluster biosynthesis. Proc Natl Acad Sci U S A. 1993:90:2754-8.

35. Agar JN, Krebs C, Frazzon J, Huynh BH, Dean DR, Johnson MK. IscU as a scaffold for iron-sulfur cluster biosynthesis: sequential assembly of [2Fe-2S] and [4Fe-4S] clusters in IscU. Biochemistry. 2000;39:7856-62.

36. Chandramouli K, Unciuleac MC, Naik S, Dean DR, Huynh BH, Johnson MK. Formation and properties of [4Fe-4S] clusters on the IscU scaffold protein. Biochemistry. 2007:46:6804-11.

37. Gardner PR, Fridovich I. Inactivation-reactivation of aconitase in Escherichia coli. A sensitive measure of superoxide radical. J Biol Chem. 1992;267:8757-63.

38. Tian $T, H e H$, Liu XQ. The SufBCD protein complex is the scaffold for ironsulfur cluster assembly in Thermus thermophiles HB8. Biochem Biophys Res Commun. 2014;443:376-81.

39. Unciuleac MC, Chandramouli K, Naik S, Mayer S, Huynh BH, Johnson MK, et al. In vitro activation of apo-aconitase using a [4Fe-4S] cluster-loaded form of the IscU [Fe-S] cluster scaffolding protein. Biochemistry. 2007;46:6812-21.

40. Wollers S, Layer G, Garcia-Serres R, Signor L, Clemancey M, Latour JM, et al. Iron-sulfur (Fe-S) cluster assembly: the SufBCD complex is a new type of FeS scaffold with a flavin redox cofactor. J Biol Chem. 2010;285:23331-41.

41. Rauch BJ, Perona JJ. Efficient sulfide assimilation in Methanosarcina acetivorans is mediated by the MA1715 protein. J Bacteriol. 2016;198:1974-83.

42. Liu Y, Sieprawska-Lupa M, Whitman WB, White RH. Cysteine is not the sulfur source for iron-sulfur cluster and methionine biosynthesis in the methanogenic archaeon Methanococcus maripaludis. J Biol Chem. 2010;285:31923-9.

43. Lyu Z, Lu Y. Metabolic shift at the class level sheds light on adaptation of methanogens to oxidative environments. ISME J. 2018;12:411-23.

44. Whitman WB, Ankwanda E, Wolfe RS. Nutrition and carbon metabolism of Methanococcus voltae. J Bacteriol. 1982;149:852-63.

45. Angel $\mathrm{R}$, Claus $\mathrm{P}$, Conrad R. Methanogenic archaea are globally ubiquitous in aerated soils and become active under wet anoxic conditions. ISME J. 2012;6:847-62

46. Marinoni EN, de Oliveira JS, Nicolet Y, Raulfs EC, Amara P, Dean DR, et al. (IscS-IscU)2 complex structures provide insights into Fe2S2 biogenesis and transfer. Angew Chem. 2012;51:5439-42.

47. Pagnier A, Nicolet $Y$, Fontecilla-Camps JC. IscS from Archaeoglobus fulgidus has no desulfurase activity but may provide a cysteine ligand for [FeS] cluster assembly. Biochim Biophys Acta. 2014;1853:1457-63.

48. Yamanaka Y, Zeppieri L, Nicolet Y, Marinoni EN, de Oliveira JS, Odaka M, et al. Crystal structure and functional studies of an unusual L-cysteine desulfurase from Archaeoglobus fulgidus. Dalton Trans. 2013;42:3092-9.

49. Chandramouli $\mathrm{K}$, Johnson MK. HscA and $\mathrm{HscB}$ stimulate [2Fe-2S] cluster transfer from IsCU to apoferredoxin in an ATP-dependent reaction. Biochemistry. 2006:45:11087-95.
50. Tanaka N, Kanazawa M, Tonosaki K, Yokoyama N, Kuzuyama T, Takahashi Y. Novel features of the ISC machinery revealed by characterization of Escherichia coli mutants that survive without iron-sulfur clusters. Mol Microbiol. 2016:99:835-48.

51. Liu Y, Beer LL, Whitman WB. Sulfur metabolism in archaea reveals novel processes. Environ Microbiol. 2012;14:2632-44.

52. Guss AM, Rother M, Zhang JK, Kulkarni G, Metcalf WW. New methods for tightly regulated gene expression and highly efficient chromosomal integration of cloned genes for Methanosarcina species. Archaea. 2008;2: 193-203.

53. Jennings ME, Lessner FH, Karr EA, Lessner DJ. The [4Fe-4S] clusters of Rpo3 are key determinants in the post Rpo3/Rpo11 heterodimer formation of RNA polymerase in Methanosarcina acetivorans; 2016. MicrobiologyOpen.

54. Sowers KR, Boone JE, Gunsalus RP. Disaggregation of Methanosarcina spp. and growth as single cells at elevated osmolarity. Appl Environ Microbiol. 1993;59:3832-9.

55. Wolin EA, Wolin MJ, Wolfe RS. Formation of methane by bacterial extracts. J Biol Chem. 1963;238:2882-6.

56. Beinert $\mathrm{H}$. Semi-micro methods for analysis of labile sulfide and of labile sulfide plus sulfane sulfur in unusually stable iron-sulfur proteins. Anal Biochem. 1983;131:373-8.

57. Welander PV, Metcalf WW. Mutagenesis of the C1 oxidation pathway in Methanosarcina barkeri: new insights into the Mtr/Mer bypass pathway. J Bacteriol. 2008;190:1928-36.

58. Metcalf WW, Zhang JK, Apolinario E, Sowers KR, Wolfe RS. A genetic system for Archaea of the genus Methanosarcina: liposome-mediated transformation and construction of shuttle vectors. Proc Natl Acad Sci U S A. $1997 ; 94: 2626-31$

\section{Publisher's Note}

Springer Nature remains neutral with regard to jurisdictional claims in published maps and institutional affiliations.

Ready to submit your research? Choose BMC and benefit from:

- fast, convenient online submission

- thorough peer review by experienced researchers in your field

- rapid publication on acceptance

- support for research data, including large and complex data types

- gold Open Access which fosters wider collaboration and increased citations

- maximum visibility for your research: over $100 \mathrm{M}$ website views per year

At $\mathrm{BMC}$, research is always in progress.

Learn more biomedcentral.com/submission 